\title{
In Vitro Nociceptor Neuroplasticity Associated with In Vivo Opioid-Induced Hyperalgesia
}

\author{
-Eugen V. Khomula, Dioneia Araldi, and Jon D. Levine \\ Departments of Medicine and Oral Surgery and Division of Neuroscience, University of California at San Francisco, San Francisco, California 94143
}

Opioid-induced hyperalgesia $(\mathrm{OIH})$ is a serious adverse event produced by opioid analgesics. Lack of an in vitro model has hindered study of its underlying mechanisms. Recent evidence has implicated a role of nociceptors in OIH. To investigate the cellular and molecular mechanisms of $\mathrm{OIH}$ in nociceptors, in vitro, subcutaneous administration of an analgesic dose of fentanyl $(30 \mu \mathrm{g} / \mathrm{kg}$, s.c.) was performed in vivo in male rats. Two days later, when fentanyl was administered intradermally $(1 \mu \mathrm{g}$, i.d.), in the vicinity of peripheral nociceptor terminals, it produced mechanical hyperalgesia $(\mathrm{OIH})$. Additionally, $2 \mathrm{~d}$ after systemic fentanyl, rats had also developed hyperalgesic priming (opioid-primed rats), long-lasting nociceptor neuroplasticity manifested as prolongation of prostaglandin $\mathrm{E}_{2}\left(\mathrm{PGE}_{2}\right)$ hyperalgesia. $\mathrm{OIH}$ was reversed, in vivo, by intrathecal administration of cordycepin, a protein translation inhibitor that reverses priming. When fentanyl $(0.5 \mathrm{nM})$ was applied to dorsal root ganglion (DRG) neurons, cultured from opioid-primed rats, it induced a $\mu$-opioid receptor (MOR)-dependent increase in $\left[\mathrm{Ca}^{2+}\right]_{\mathrm{i}}$ in $26 \%$ of small-diameter neurons and significantly sensitized (decreased action potential rheobase) weakly IB4 ${ }^{+}$and IB4 ${ }^{-}$neurons. This sensitizing effect of fentanyl was reversed in weakly IB4 ${ }^{+}$DRG neurons cultured from opioid-primed rats after in vivo treatment with cordycepin, to reverse of OIH. Thus, in vivo administration of fentanyl induces nociceptor neuroplasticity, which persists in culture, providing evidence for the role of nociceptor MOR-mediated calcium signaling and peripheral protein translation, in the weakly IB4-binding population of nociceptors, in OIH.

Key words: calcium; excitability; fentanyl; hyperalgesic priming; mu-opioid receptor (MOR); opioid-induced hyperalgesia (OIH)

Significance Statement

Clinically used $\mu$-opioid receptor agonists such as fentanyl can produce hyperalgesia and hyperalgesic priming. We report on an in vitro model of nociceptor neuroplasticity mediating this opioid-induced hyperalgesia $(\mathrm{OIH})$ and priming induced by fentanyl. Using this model, we have found qualitative and quantitative differences between cultured nociceptors from opioid-naive and opioid-primed animals, and provide evidence for the important role of nociceptor $\mu$-opioid receptor-mediated calcium signaling and peripheral protein translation in the weakly IB4-binding population of nociceptors in OIH. These findings provide information useful for the design of therapeutic strategies to alleviate $\mathrm{OIH}$, a serious adverse event of opioid analgesics.

\section{Introduction}

Opioids remain among the most effective treatments for moderate-to-severe acute pain; and, are also used as a treatment for chronic pain syndromes, which affect approximately one-third of the population in the US and Europe (Andersson et al., 1993; Johannes et al., 2010; Gaskin and Richard, 2012; van Hecke et al., 2013; Nahin, 2015). However, in a substantial number of patients opioids produce serious adverse events, including opioidinduced hyperalgesia $(\mathrm{OIH})$, a hypersensitivity to painful stimuli

\footnotetext{
Received May 22, 2019; revised July 2, 2019; accepted July 4, 2019.

Author contributions: E.V.K., D.A., and J.D.L. designed research; E.V.K. and D.A. performed research; E.V.K. and D.A. analyzed data; E.V.K., D.A., and J.D.L. wrote the paper.

This work was supported by the National Institutes of Health (Grant NS084545).

The authors declare no competing financial interests.

Correspondence should be addressed to Jon D. Levine at jon.levine@ucsf.edu.

https://doi.org/10.1523/JNEUROSCI.1191-19.2019

Copyright $\odot 2019$ the authors
}

(hyperalgesia) and pain exacerbation. Although OIH can overlap with acute opioid tolerance and withdrawal, there is preclinical and clinical evidence that they are, at least in part, distinct entities (Angst and Clark, 2006; Silverman, 2009; Eisenberg et al., 2015; Yi and Pryzbylkowski, 2015; Roeckel et al., 2016; Weber et al., 2017). Clinically, OIH is associated with long term use in pain patients (Chu et al., 2006; Crofford, 2010; Fletcher and Martinez, 2014; Carullo et al., 2015) and opioid addicts (Compton et al., 2001, 2012). It can, however, develop in healthy human volunteers, even when opioids have been given on a short-term basis, especially when a fentanyl class opioid is administered (Fishbain et al., 2009; Ruscheweyh et al., 2011; Mauermann et al., 2016); and, acutely after its administration for surgery (Yildirim et al., 2014; Chang et al., 2018). OIH, which can develop rapidly, and often goes unrecognized, may occur much more frequently than generally thought (Zylicz and Twycross, 2008). In preclinical models, a few doses of fentanyl, or a single dose of heroin, were 
sufficient to induce OIH (Laulin et al., 1998; Celerier et al., 2000).

We have recently shown that depending on the opioid used, and its dose and route of administration, opioids are capable of inducing acute hyperalgesia, even after a single administration (Araldi et al., 2015, 2018b,c, 2019; Ferrari et al., 2019). In particular, clinically used $\mu$-opioid receptor (MOR) agonists, fentanyl (Araldi et al., 2018c) and morphine (Araldi et al., 2019; Ferrari et al., 2019), as well as the highly selective MOR agonist, DAMGO (Araldi et al., 2015, 2017, 2018a), produce OIH and hyperalgesic priming, a form of nociceptor neuroplasticity characterized by a persistent increase in responsivity of nociceptors to proalgesic mediators (Ferrari et al., 2010; Joseph and Levine, 2010b; Alvarez et al., 2014; Araldi et al., 2015; Khomula et al., 2017). Recent evidence has implicated a role of the action of MOR agonists on primary afferent nociceptors in OIH (Corder et al., 2017). We have suggested a role of nociceptor calcium signaling in OIH (Araldi et al., 2018c). A MORindependent modulation of voltage-gated calcium channels and acid-sensing ion channels (ASICs) has also been implicated (Iegorova et al., 2010; Chizhmakov et al., 2015; Zaremba and RuizVelasco, 2019). Lack of an in vitro model of OIH has made it difficult to study its underlying mechanisms at the cellular level.

We report on an in vitro model of $\mathrm{OIH}$ induced by systemic opioid administration. Fentanyl was administered in vivo, followed by: (1) fentanyl injected intradermally, at the nociceptor peripheral terminal, or (2) fentanyl applied in vitro on cultured DRG neurons. This has allowed us to examine in vitro correlates of $\mathrm{OIH}$, including mechanisms that maintain $\mathrm{OIH}$.

\section{Materials and Methods}

Animals. Experiments were performed on 220-420 g adult male Sprague Dawley rats (Charles River Laboratories). Experimental animals were housed three per cage, under a $12 \mathrm{~h}$ light/dark cycle in a temperature- and humidity-controlled animal care facility at the University of California, San Francisco. Food and water were available ad libitum. Nociceptive testing was performed between 9:00 A.M. and 5:00 P.M. Experimental protocols, which were approved by the Institutional Animal Care and Use Committee at the University of California, San Francisco, adhered to the National Institutes of Health Guide for the Care and Use of Laboratory Animals. Effort was made to minimize number of animals used and their suffering.

Nociceptive threshold testing. Mechanical nociceptive threshold was measured using an Ugo Basile Analgesymeter (Randall-Selitto pawwithdrawal device, Stoelting), which applies a linearly increasing mechanical force to the dorsum of a rat's hindpaw, with a dome-shaped plinth, as described previously (Taiwo and Levine, 1989; Taiwo et al., 1989; Araldi et al., 2015, 2017; Ferrari and Levine, 2015). Rats were placed in cylindrical acrylic restrainers that provide ventilation, and allow extension of the hind legs from lateral ports to assess nociceptive threshold, while minimizing restraint stress. To acclimatize rats to the testing procedure, they were placed in restrainers for $40 \mathrm{~min}$ before starting training sessions ( 3 consecutive days of training) and for $30 \mathrm{~min}$ before experimental manipulations. Nociceptive threshold was defined as the force, in grams, at which the rat withdrew its paw. Baseline nociceptive threshold was defined as the mean of three readings taken before injection of test agents. In each experiment, only one paw per rat was used. Each experiment was performed on a different group of rats ( 1 paw/rat in 6 rats/ group). The individual performing behavioral experiments was blinded to the treatments rats received.

Drugs and routes of administration. The following compounds were used: cordycepin $5^{\prime}$-triphosphate sodium salt (a protein translation inhibitor), CTOP (a MOR antagonist), fentanyl citrate salt (a MOR agonist), prostaglandin $\mathrm{E}_{2}\left(\mathrm{PGE}_{2}\right.$, a direct-acting nociceptor-sensitizing agent), SU6656 (a Src family kinase inhibitor), and U0126 (a MAPK/ERK inhibitor), all of which were purchased from Sigma-Aldrich.
Stock solution of $\mathrm{PGE}_{2}(1 \mu \mathrm{g} / \mu \mathrm{l})$ was prepared in $100 \%$ ethanol and additional dilutions made with physiological saline $(0.9 \% \mathrm{NaCl})$, to prepare the final solution $(100 \mathrm{ng} / 5 \mu \mathrm{l})$ used in experiments, yielding a final ethanol concentration of $2 \%$. In vivo control experiments have previously shown that ethanol in this concentration had no effect on the mechanical threshold (Ferrari et al., 2016). Fentanyl and cordycepin were dissolved in saline. All other drugs were dissolved in 100\% DMSO (Sigma-Aldrich) and further diluted in saline containing 2\% Tween 80 (Sigma-Aldrich). The final concentration of DMSO and Tween 80 was $\sim 2 \%$.

Intradermal administration of fentanyl $(1 \mu \mathrm{g} / 5 \mu \mathrm{l})$ and $\mathrm{PGE}_{2}(100$ $\mathrm{ng} / 5 \mu \mathrm{l}$ ) was performed on the dorsum of the hindpaw using a 30 -gauge hypodermic needle adapted to a $50 \mu \mathrm{l}$ Hamilton syringe by a segment of $\mathrm{PE}-10$ polyethylene tubing (BD Biosciences). Intrathecal administration of cordycepin and the combination of SU6656 and U0126 were performed in rats briefly anesthetized with $2.5 \%$ isoflurane (Phoenix Pharmaceuticals) in $97.5 \% \mathrm{O}_{2}$ using a 29 -gauge hypodermic needle (300 unit/ $\mu$ l syringe) inserted into the subarachnoid space, between the L4 and $\mathrm{L} 5$ vertebrae. The maximum intrathecal volume administered was 20 $\mu \mathrm{l}$; cordycepin $(4 \mu \mathrm{g})$ was dissolved in saline and injected intrathecally in a volume of $20 \mu \mathrm{l}$; and, the intrathecal injection of the combination of SU6656 $(10 \mu \mathrm{g})$ and U0126 $(10 \mu \mathrm{g})$ was performed in a volume of $10 \mu \mathrm{l}$ each (Araldi et al., 2018c). Ten minutes after intrathecal treatments, fentanyl $(1 \mu \mathrm{g} / 5 \mu \mathrm{l})$ was injected intradermally, on the dorsum of the hindpaw. The intrathecal site of injection was confirmed by a sudden flick of the rat's tail, a reflex that is evoked by accessing the subarachnoid space followed by bolus injection (Mestre et al., 1994).

Systemic (subcutaneous) administration of fentanyl was performed at the nape of the neck (Araldi et al., 2018c). Rats received an injection of fentanyl (30 $\mu \mathrm{g} / \mathrm{kg}$, s.c.) diluted in saline and administered subcutaneously (100 $\mu \mathrm{l} / 100 \mathrm{~g}$ body weight).

Culture of dorsal root ganglion (DRG) neurons. Primary cultures of DRG neurons were made from adult male Sprague Dawley rats (220-235 g), as described previously (Ferrari et al., 2016, 2018; Khomula et al., 2017; Araldi et al., 2018c). In brief, under isoflurane anesthesia, rats were decapitated, and the dorsum of the vertebral column surgically removed; $\mathrm{L}_{4}$ and $\mathrm{L}_{5}$ DRGs were rapidly extracted, bilaterally, chilled and desheathed in Hanks' balanced salt solution (HBSS) on ice. Ganglia were then treated with $0.125 \%$ collagenase P (Worthington Biochemical) in HBSS for $90 \mathrm{~min}$ at $37^{\circ} \mathrm{C}$, and then treated with $0.25 \%$ trypsin (Worthington Biochemical) in calcium- and magnesium-free PBS (Invitrogen Life Technologies) for $10 \mathrm{~min}$, followed by three washes and then trituration in Neurobasal-A medium (Invitrogen Life Technologies) to produce a single-cell suspension. This suspension was centrifuged at 1000 RPM for $3 \mathrm{~min}$ and resuspended in Neurobasal-A medium supplemented with $50 \mathrm{ng} / \mathrm{ml}$ nerve growth factor, $100 \mathrm{U} / \mathrm{ml}$ penicillin/streptomycin and B-27 (Invitrogen Life Technologies). Cells were then plated on coverslips and incubated at $37^{\circ} \mathrm{C}$ in $3.5 \% \mathrm{CO}_{2}$ for at least $24 \mathrm{~h}$ before use in experiments.

Microscopy and fluorescence imaging. The bright-field imaging system consisted of an inverted microscope (Eclipse TE-200, Nikon) with epifluorescence using a xenon lamp (Lambda LS, Sutter Instruments ) for excitation (Ferrari et al., 2018). Illumination was controlled by a Lambda 10-2 filter wheel and Lambda SC Smart Shutter controllers (Sutter Instruments); an Andor Clara Interline CCD camera (Andor Technology) was used for high-resolution digital image acquisition. MetaFluor software (Molecular Devices) provided computer interface and controlled the whole system as well as being used for image processing. A Plan Fluor objective $(20 \times \mathrm{UV}$, numerical aperture 0.50; Nikon) was used for both fluorescent and transmitted light imaging with phase contrast illumination.

In vitro recordings. Cultured DRG neurons were used $24-96 \mathrm{~h}$ after dissociation and plating, for in vitro experiments. At least three rats/ culture preparation were used for each experimental series. Within the text, " $n$ " refers to the number of neurons. Cells were identified as neurons by their double birefringent plasma membranes (Cohen et al., 1968; Landowne, 1993). Although small-, medium-, and large-sized neurons were routinely observed in the same preparation, this study focused on cells with soma diameter $<30 \mu \mathrm{m}$ (small DRG neurons), predominantly 
representing C-type nociceptors (Harper and Lawson, 1985; Gold et al., 1996; Petruska et al., 2000, 2002; Woolf and Ma, 2007). After mounting a coverslip in the recording chamber, the culture medium was replaced with Tyrode's solution containing $140 \mathrm{~mm} \mathrm{NaCl}, 4 \mathrm{~mm} \mathrm{KCl}, 2 \mathrm{~mm} \mathrm{MgCl}$, $2 \mathrm{~mm} \mathrm{CaCl}_{2}, 10 \mathrm{~mm}$ glucose, $10 \mathrm{~mm}$ HEPES, and adjusted to $\mathrm{pH} 7.4$ with $\mathrm{NaOH}$; osmolarity is $310 \mathrm{mOsm} / \mathrm{kg}$ (Ferrari et al., 2016, 2018; Khomula et al., 2017; Araldi et al., 2018c). Tyrode's solution was used as external perfusion solution in the in vitro experiments. Fluorescent dyes and drugs used in vitro were diluted to their final concentration in this solution and applied. The volume of the recording chamber was $150 \mu \mathrm{l}$. The perfusion system was gravity driven at a flow rate of $0.5-1 \mathrm{ml} / \mathrm{min}$. All experiments were performed at room temperature, $20-23^{\circ} \mathrm{C}$.

In vitro IB4 binding. Cells were incubated in Tyrode's solution supplemented with $10 \mu \mathrm{g} / \mathrm{ml} \mathrm{IB} 4$ conjugated to Alexa Fluor 488 dye (Invitrogen Life Technologies) for 10-12 min in the dark. After washout, fluorescent images were captured during the first $15 \mathrm{~min}$ of each experiment using a standard GFP filter set (Chroma Technology). Cells demonstrating bright fluorescence and a halo around the neuronal plasma membrane were recognized as $\mathrm{IB}_{4}^{+}$(strongly positive, if intensity $>40 \%$ of maximum for the selected field of view, and weakly positive if intensity is in the range $20-40 \%$ of maximum), whereas those having intensity $<20 \%$ of maximum were considered IB4 ${ }^{-}$(Fang et al., 2006; Khomula et al., 2013, 2017; Ferrari et al., 2016, 2018).

Calcium imaging. Ratiometric calcium imaging was performed using the fluorescent calcium indicator dye fura-2 acetoxymethyl ester (fura-2 AM) as described previously (Ferrari et al., 2016; Khomula et al., 2017; Araldi et al., 2018c). Briefly, neurons were loaded with $5 \mu \mathrm{M}$ fura-2 AM by incubation for $20 \mathrm{~min}$ in the recording chamber. Then the chamber was perfused with Tyrode's solution for $10 \mathrm{~min}$ before the beginning of the recording to allow for complete de-esterification of the fura-2 AM. Measurement of the intracellular concentration of free calcium ions $\left(\left[\mathrm{Ca}^{2+}\right]_{\mathrm{i}}\right)$ was performed by ratiometric imaging. Fluorescence was excited at 340 and $380 \mathrm{~nm}$ for $2-10 \mathrm{~ms}$, and the emitted light was long filtered at $520 \mathrm{~nm}$ using a standard Fura-2 filter set (Chroma Technology). Using MetaFluor software (Molecular Devices), corresponding pairs of digital images were acquired every $1-10 \mathrm{~s}$ (depending on the rate of the examined process, to minimize UV exposure and excitotoxicity); the fluorescence ratio (F340/F380) was calculated on a pixel-by-pixel basis with background correction and averaged for the region of interest defined for each neuron. Fluorescence ratio was used to characterize $\left[\mathrm{Ca}^{2+}\right]_{\mathrm{i}}$ without recalculation into concentration.

In vitro patch-clamp electrophysiology. Whole-cell patch-clamp recordings in current-clamp mode were made to assess changes in the excitability of cultured DRG neurons. Commonly used protocols or their minor modifications were used to elicit action potentials (APs) (Hendrich et al., 2013; Duzhyy et al., 2015; Saloman et al., 2016; ViatchenkoKarpinski and Gu, 2016; Ferrari et al., 2018).

Recording electrodes were fabricated from borosilicate glass capillaries (0.84/1.5 mm i.d./o.d., Warner Instruments) using a Flaming/Brown P-87 puller (Sutter Instrument). Recording electrode resistance was $\sim 5$ $\mathrm{M} \Omega$ after being filled with solution containing (in $\mathrm{mM}$ ) $130 \mathrm{KCl}, 10$ HEPES, 10 EGTA, $1 \mathrm{CaCl}_{2}, 5 \mathrm{MgATP}$, and $1 \mathrm{Na}-\mathrm{GTP}$, pH 7.2 (adjusted with Tris-base), $300 \mathrm{mOsm}$ (measured by Wescor Vapro 5520 osmometer, ELITech Group) (Ferrari et al., 2018). Junction potential was not adjusted. Series resistance was $<20 \mathrm{M} \Omega$ at the end of recordings and was not compensated. Recordings were made with an Axon MultiClamp 700 $\mathrm{B}$ amplifier, filtered at $10 \mathrm{kHz}$, and sampled at $20 \mathrm{kHz}$ using Axon Digidata 1550B controlled by pCLAMP 10 software (all from Molecular Devices).

Holding current (in current-clamp mode) was adjusted to maintain membrane potential at $-70 \mathrm{mV}$. Capacitance, membrane input and access resistance was estimated before and 3-5 min after the application of drugs with the aid of amplifier circuitry (during a short switch to voltageclamp mode).

Rheobase, the minimum magnitude of a current step that elicited an AP, was determined from a protocol using increasing square wave current pulses. To estimate rheobase, a series of current steps, with an initial step to $-50 \mathrm{pA}$, followed by $+200 \mathrm{pA}$ increments $(-50,+150,+350, \ldots)$ was applied until APs were elicited. Then the protocol was adjusted to 5-6 pulses with step size of $5-10 \%$ of the rheobase estimate (2-3 subthreshold stimuli and 2-3 with AP generation, to achieve precision and to avoid overstimulation/desensitization) and applied every 3 min (Ferrari et al., 2018).

Drugs were applied at least $10 \mathrm{~min}$ after the establishment of wholecell configuration, when baseline current was stable. Change in rheobase, expressed as percentage decrease compared with a preadministration baseline, was used as a measure of drug-induced sensitization (Ferrari et al., 2018).

Data analysis. All data are presented as mean \pm SEM of $n$ independent observations. Statistical comparisons were made using GraphPad Prism 7.0 statistical software. A $p$-value $<0.05$ was considered statistically significant.

In behavioral experiments, the dependent variable was change in mechanical paw-withdrawal threshold. As described in the legends of Figures 1, 2, and 3, no significant difference was observed between mechanical nociceptive thresholds measured just before each consequent administration of test agents, used as corresponding baselines for their effects. The magnitude of each agent-induced effect was expressed as percentage change of mechanical nociceptive thresholds from baseline. Average mechanical nociceptive threshold before systemic vehicle or fentanyl was $141 \pm 2 \mathrm{~g}(n=54)$.

Calcium-imaging results are presented as magnitude of responses to test agent applications. The amplitude of response was measured as the difference between fluorescence ratio maximum achieved during $5 \mathrm{~min}$ administration and the preadministration baseline. In electrophysiological experiments, change in rheobase, expressed as percentage decrease compared with a preadministration baseline, was used as a measure of fentanyl-induced increase of electrical excitability.

As described in detail in the figure legends (or its description in the results), the following statistical tests were used: paired and unpaired Student's $t$ test (see Fig. $1 B$ ), two-way repeated-measures ANOVA followed by Bonferroni's post hoc test (see Figs. $1 A, 2$, and $3 B$ ), one-way ANOVA followed by Bonferroni's post hoc test (see Fig. 3A), D'Agostino and Pearson normality test (see Figs. $4 B$ and 6), one-way ANOVA followed by Dunnet's post hoc test (see Fig. $4 B$ ), two-sided Fisher's exact test (see Figs. $4 B, 6$, and $7 A$ ), and $\chi^{2}$ test (see Fig. $7 A$ ) for proportions, twoway ANOVA followed by Sidak's post hoc test (see Fig. 5), two-way ANOVA followed by Holm-Sidak's post hoc test (see Fig. $7 B$ ).

\section{Results}

\section{Inhibition of protein translation reverses $\mathrm{OIH}$}

We have previously demonstrated that several inflammatory mediators, which act as agonists at cell surface receptors on nociceptor (Aley et al., 2000; Reichling and Levine, 2009; Bogen et al., 2012; Ferrari et al., 2013a,b) and MOR agonists (e.g., DAMGO, fentanyl, and morphine) (Araldi et al., 2015, 2017, 2018a,c; Ferrari et al., 2019), produce hyperalgesic priming, a form of nociceptor neuroplasticity thought to contribute to the transition from acute to chronic pain. A key feature of the primed nociceptor is that it responds to pronociceptive mediators, prototypically prostaglandin $\mathrm{E}_{2}\left(\mathrm{PGE}_{2}\right)$, with markedly enhanced and prolonged mechanical hyperalgesia (Aley et al., 2000; Parada et al., 2003b, 2005; Reichling and Levine, 2009; Ferrari et al., 2014, 2016, 2019; Araldi et al., 2015, 2017, 2018a,c, 2019; Khomula et al., 2017). Intradermal MOR agonists, in a dose that does not affect mechanical nociceptive threshold in opioid-naive rats, induces robust hyperalgesia in rats previously treated systemically with a MOR agonist (Araldi et al., 2018a).

We investigated whether the systemic administration of an analgesic dose of fentanyl $(30 \mu \mathrm{g} / \mathrm{kg})$ in vivo produces nociceptor neuroplasticity. First, we determined whether such treatment alone induces hyperalgesia $(\mathrm{OIH})$. Rats were treated systemically with fentanyl (30 $\mu \mathrm{g} / \mathrm{kg}$, s.c.) or vehicle (saline) and mechanical nociceptive threshold evaluated 1, 2 and $3 \mathrm{~h}$ later. An increase in mechanical nociceptive threshold (analgesia) was observed $1 \mathrm{~h}$ 
after systemic fentanyl (Fig. $1 A ; F_{(1,10)}=23.0, p=0.0007$, when the mechanical nociceptive threshold is compared between vehicle- and fentanyl-treated groups, $1 \mathrm{~h}$ after systemic administration; two-way repeated-measures ANOVA), with nociceptive threshold returning to prefentanyl baseline by $2 \mathrm{~h}$ (Fig. 1A); hyperalgesia was not detected. However, there is evidence that opioids, including fentanyl, can induce hyperalgesia 1-2 d after its initial administration (Laulin et al., 1998; Celerier et al., 2000). Therefore, the mechanical nociceptive threshold was also measured $2 \mathrm{~d}(48 \mathrm{~h})$ after the initial systemic administration of vehicle or fentanyl, at which time it was not different from the baseline before the systemic treatment (Fig. 1A), indicating that neither acute nor delayed onset hyperalgesia developed after systemic administration of fentanyl. At this time point, when all detectable effects of systemic fentanyl on nociceptive threshold had dissipated, rats received an intradermal injection of fentanyl $(1 \mu \mathrm{g})$, on the dorsum of the hindpaw, and mechanical nociceptive threshold was evaluated at the injection site, 30 min later. Hyperalgesia induced by intradermal fentanyl $(\mathrm{OIH})$ was observed in rats previously treated with systemic fentanyl (Fig. $1 B ; t_{(10)}=$ 14.0, $p<0.0001$, when the hyperalgesia in the vehicle- and fentanyl-treated groups is compared, $30 \mathrm{~min}$ after intradermal fentanyl; Student's $t$ test). Thus, by injecting fentanyl intradermally in rats previously treated with systemic fentanyl, we were able to demonstrate the presence of $\mathrm{OIH}$ in vivo. These findings support the development of nociceptor neuroplasticity. Therefore, we also evaluated for the presence of hyperalgesic priming associated with nociceptor neuroplasticity.

To detect hyperalgesic priming, groups of rats that had been treated with systemic vehicle or fentanyl, $2 \mathrm{~d}$ prior, received an intradermal injection of $\mathrm{PGE}_{2}(100 \mathrm{ng})$ and the mechanical nociceptive threshold was evaluated $30 \mathrm{~min}$ and $4 \mathrm{~h}$ later. Hyperalgesia was present $30 \mathrm{~min}$ after injection of $\mathrm{PGE}_{2}$, in both groups (Fig. 2); however, hyperalgesia at the fourth hour, a characteristic of priming, was only present in the group previously treated with systemic fentanyl (Fig. 2; $F_{(1,10)}=113.0, p<0.0001$, when the hyperalgesia in the vehicle- and fentanyl-treated groups is compared after at the fourth hours after intradermal $\mathrm{PGE}_{2}$; two-way repeated-measures ANOVA). Thus, a systemic analgesic dose of fentanyl $(30 \mu \mathrm{g} / \mathrm{kg}$, s.c.) produces a form of neuroplasticity in nociceptors associated with $\mathrm{OIH}$ and hyperalgesic priming. Therefore, we denote these rats as fentanyl primed.

It is not known whether the priming, which is characteristically observed along with OIH (Araldi et al., 2015, 2017, 2018a,b,c; Ferrari et al., 2019), have shared mechanisms or if they are just a parallel process. Recently, we distinguished two types of hyperalgesic priming, with distinct cellular mechanisms (Araldi et al., 2015). The maintenance of type I priming is dependent on protein translation in nerve terminals (Ferrari et al., 2013b), while type II depends on simultaneous activation of Src and mitogen-activated protein kinase (MAPK) (Araldi et al., 2017). Therefore, in the present study, we investigated whether $\mathrm{OIH}$ developed in fentanyl-primed rats shares maintenance mechanisms with type I or type II priming.

Rats received systemic fentanyl ( $30 \mu \mathrm{g} / \mathrm{kg}$, s.c.), and $2 \mathrm{~d}$ later were treated intrathecally with vehicle, the protein translation inhibitor cordycepin $(4 \mu \mathrm{g})$, or the combination of an Src (SU6656, $10 \mu \mathrm{g}$ ) and a MAPK (U0126, $10 \mu \mathrm{g}$ ) inhibitor, followed 10 min later by intradermal fentanyl $(1 \mu \mathrm{g})$. Mechanical nociceptive threshold was evaluated $30 \mathrm{~min}$ after intradermal fentanyl. In both the cordycepin- and the SU6656 + U0126-combinationtreated groups, intradermal fentanyl did not induce hyperalgesia, when compared with the group treated with vehicle (Fig. 3A;
$F_{(2,15)}=57.0, p<0.0001$, when the hyperalgesia in the vehicle-, SU6656 + U0126-, and in the cordycepin-treated groups is compared $30 \mathrm{~min}$ after intradermal fentanyl; one-way ANOVA). However, 1 month after the intrathecal treatments, when fentanyl $(1 \mu \mathrm{g})$ was again injected intradermally, it ability to produce hyperalgesia was still reversed in the group previously treated with cordycepin, but not in the vehicle- and SU6656 + U0126treated groups (Fig. $3 B ; F_{(2,15)}=66.0, p<0.0001$, when the hyperalgesia in the vehicle-, SU6656 + U0126- and cordycepintreated groups is compared $30 \mathrm{~min}$ after intradermal fentanyl; two-way repeated-measures ANOVA). These findings support the suggestion that $\mathrm{OIH}$, produced by intradermal fentanyl, in fentanyl-primed rats, share a mechanism with type I priming (Ferrari et al., 2013b, 2019; Araldi et al., 2018c).The neuroplasticity induced by systemic fentanyl was persistent (long-lasting) as revealed by the ability of intradermal fentanyl to induce hyperalgesia $(\mathrm{OIH})$ even 1 month after its systemic administration.

\section{MOR-mediated increased $\left[\mathrm{Ca}^{2+}\right]_{\mathrm{i}}$ in sensory neurons from primed rats}

Calcium signals play an important role in the regulation of neuronal function (Kostyuk and Verkhratsky, 1994; Berridge et al., 2000; Hagenston and Simonetti, 2014; Luarte et al., 2018; Bandura and Feng, 2019), including type I hyperalgesic priming (Ferrari et al., 2013a; Araldi et al., 2018c). Altered calcium signaling in nociceptors can reflect both neuronal plasticity and changes in electrophysiological properties, including sensitization (Shutov et al., 2006; Khomula et al., 2013; Yu et al., 2015; Pan et al., 2016). MOR agonists have been shown to produce calcium signals in DRG neurons, in vitro (Velazquez-Marrero et al., 2014). We recently demonstrated a MOR-mediated increase in cytosolic $\mathrm{Ca}^{2+}$ concentration $\left(\left[\mathrm{Ca}^{2+}\right]_{\mathrm{i}}\right)$ in response to fentanyl $(0.5 \mathrm{nM})$, in cultured small DRG neurons from opioid-naive rats (Araldi et al., 2018c). And in vivo tests have provided evidence for a crucial role of calcium signaling in fentanyl-induced hyperalgesic priming (Araldi et al., 2018c).

We tested the hypothesis that opioid-induced calcium signals in nociceptors, cultured after in vivo administration of fentanyl, differ from the calcium signals in nociceptors from opioid-naive animals, changes that could contribute to OIH. We performed calcium imaging experiments on cultured DRG neurons isolated from animals that had received a single analgesic dose of fentanyl (30 $\mu \mathrm{g} / \mathrm{kg}$, s.c.) $24 \mathrm{~h}$ before DRG isolation (primed group) or from opioid-naive animals (control group). Based on our previous study (Araldi et al., 2018c), we used direct bath application of fentanyl $(0.5 \mathrm{~nm})$ to induce an increase in $\left[\mathrm{Ca}^{2+}\right]_{\mathrm{i}}$, in a $\mathrm{Ca}^{2+}$ containing extracellular solution. Fluorescence ratiometric calcium imaging of cultured neurons (preserving intracellular signaling pathways) was used to follow the time course of changes in $\left[\mathrm{Ca}^{2+}\right]_{\mathrm{i}}$ reported as Fura-2 F340/F380 fluorescence ratio (Fig. $4 A)$. The maximal increase in $\left[\mathrm{Ca}^{2+}\right]_{i}$, relative to baseline during 5 min administration of fentanyl was considered as response magnitude (Fig. 4B). Taking into account that hyperalgesic priming is dependent on nociceptors (Ferrari et al., 2010; Araldi et al., 2018c) we measured the $\left[\mathrm{Ca}^{2+}\right]_{\mathrm{i}}$ response to fentanyl only in small DRG neurons (soma diameter $<30 \mu \mathrm{m}$ ), the main constituent of the C-type nociceptive population of primary sensory neurons (Harper and Lawson, 1985; Gold et al., 1996; Petruska et al., 2000, 2002; Woolf and Ma, 2007).

In neurons from the opioid-naive control group, we only observed relatively small, normally distributed, increases in $\left[\mathrm{Ca}^{2+}\right]_{\mathrm{i}}$ $(0.0153 \pm 0.0017$ arbitrary units [a.u.], $n=28, \mathrm{SD}=0.0087)$. In contrast, responses in neurons from primed rats revealed much 
A

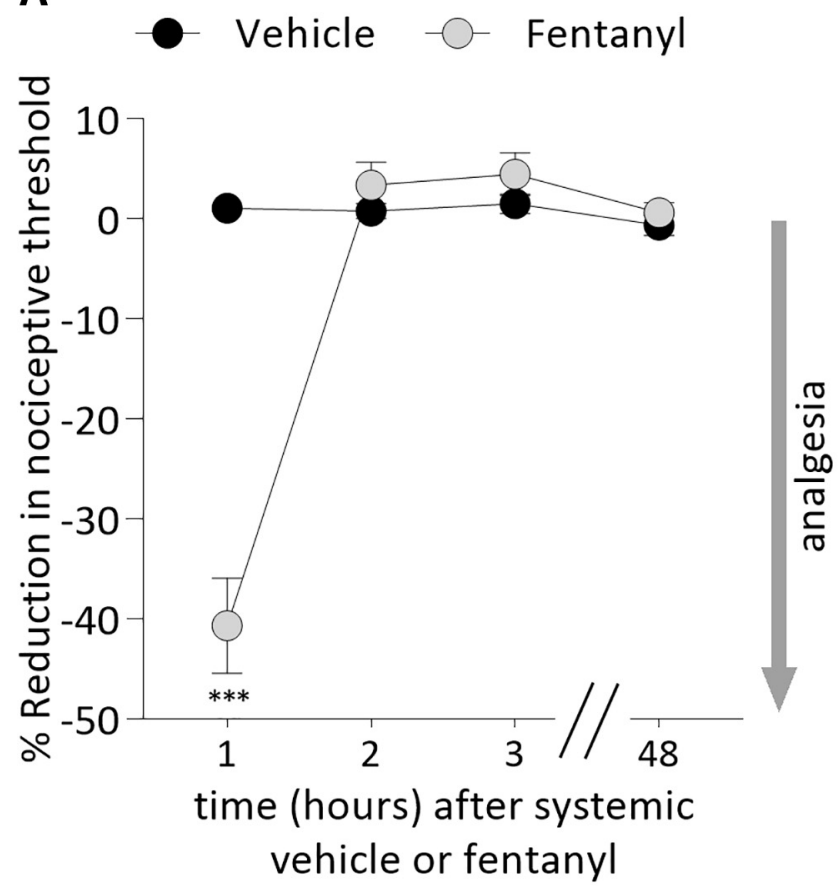

B

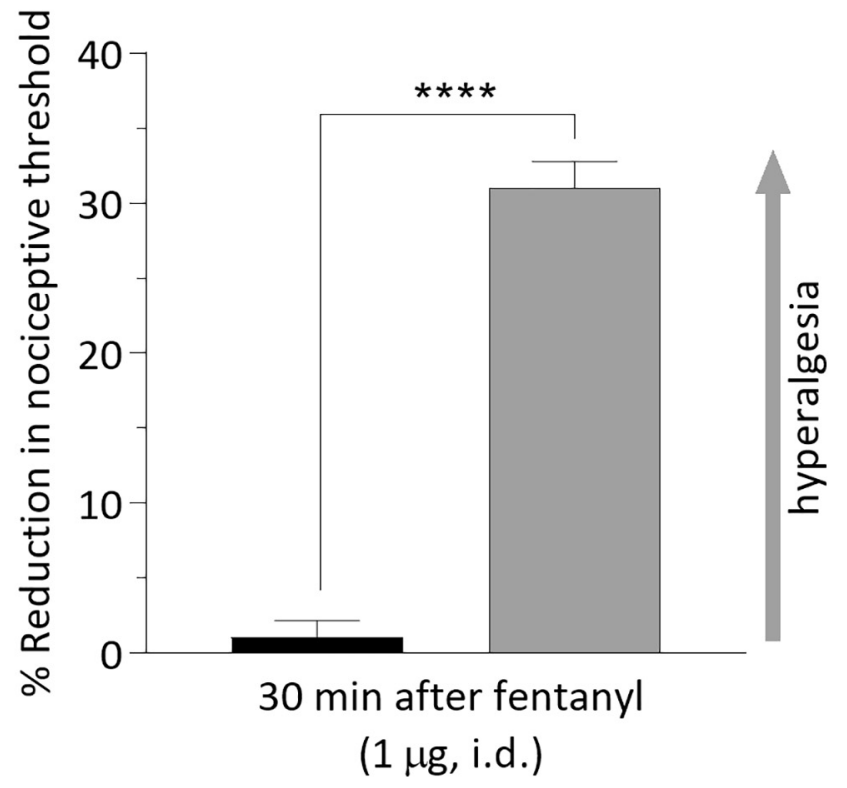

Figure 1. Effect of fentanyl on mechanical nociceptive threshold. A, Male rats were treated systemically (subcutaneous, s.c.) with an analgesic dose of fentanyl ( $30 \mu \mathrm{g} / \mathrm{kg}$, s.c.) or vehicle (saline, $100 \mu \mathrm{l} / 100 \mathrm{~g}$ body weight, s.c.). Mechanical nociceptive threshold was evaluated 1, 2, 3 , and $48 \mathrm{~h}$ after each treatment. Systemic fentanyl induced analgesia measured $1 \mathrm{~h}$ after administration $\left(F_{(1,10)}=23,{ }^{* * *} p=0.0007\right.$, when the mechanical nociceptive threshold was compared between vehicle and fentanyl, $1 \mathrm{~h}$ after systemic administration; two-way repeatedmeasures ANOVA followed by Bonferroni post hoc test). By $2 \mathrm{~h}$ after systemic fentanyl no significant difference in nociceptive threshold was observed between vehicle- and fentanyltreated rats. ( $n=6$ paws per group). $\boldsymbol{B}$, A different group of rats was treated systemically with fentanyl (30 $\mu \mathrm{g} / \mathrm{kg}$, s.c.) or vehicle (saline, s.c.). Two days later, fentanyl was injected intradermally $(1 \mu \mathrm{g} / 5 \mu \mathrm{l})$, in both groups, to evaluate for the presence of $0 \mathrm{lH}$; the mechanical nociceptive threshold was evaluated 30 min after intradermal fentanyl. Nociceptive threshold

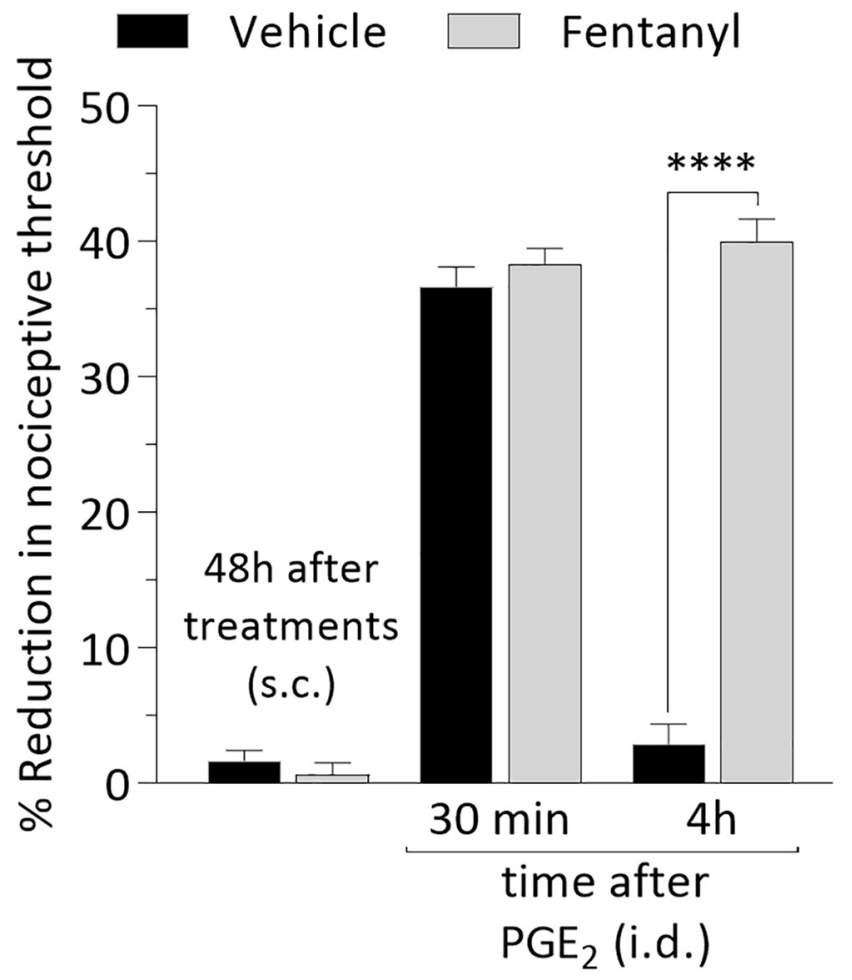

Figure 2. Systemic fentanyl induces hyperalgesic priming. Rats received vehicle (saline, s.c.) or an analgesic dose of fentanyl (30 $\mu \mathrm{g} / \mathrm{kg}$, s.c.). Forty-eight hours later, PGE $2(100 \mathrm{ng} / 5 \mu \mathrm{l})$ was injected intradermally on the dorsum of the hindpaw and mechanical nociceptive threshold evaluated $30 \mathrm{~min}$ and $4 \mathrm{~h}$ later. Nociceptive threshold before intradermal injection of $\mathrm{PGE}_{2}$ was not different from presystemic fentanyl baseline $\left(t_{5}=1.6 ; p=0.17\right.$, for the vehicle-treated group and, $t_{5}=0.70 ; p=0.52$, for the fentanyl-treated group; paired Student's $t$ test). PGE 2 induced hyperalgesia, $30 \mathrm{~min}$ after injection, in both vehicle- and fentanyl-treated groups. However, prolongation of $\mathrm{PGE}_{2}$-induced hyperalgesia, at the fourth hour, was present only in the group previously treated with fentanyl $\left(F_{(1,10)}=113,{ }^{* * * *} p<0.0001\right.$; when the hyperalgesia in the vehicle- and fentanyl-treated groups is compared at the fourth hour after intradermal PGE ; two-way repeated-measures ANOVA followed by Bonferroni post hoc test). Thus, systemic administration of a single analgesic dose of fentanyl (30 $\mu \mathrm{g} / \mathrm{kg}$, s.c.) induces hyperalgesic priming, as shown by subsequent prolongation of $\mathrm{PGE}_{2}$ hyperalgesia. ( $n=6$ paws per group).

greater variability $(0.031 \pm 0.006$ a.u., $n=34$; $\mathrm{SD}=0.038$ is bigger than the mean itself) and had a distribution significantly different from Gaussian (D'Agostino and Pearson normality test: $\mathrm{K} 2=35, p<0.0001)$. These responses could be separated visually into two subgroups: values close to responses in unprimed nociceptors and values at least three times bigger. We therefore set a threshold of 0.032 ([mean $+2 \times \mathrm{SD}]$ in control), dividing the neurons from primed rats into responders $(0.078 \pm 0.017$ a.u., $\mathrm{SD}=0.050$ a.u., $n=9$ of 34$)$ and nonresponders $(0.0146 \pm$ 0.0008 a.u., $\mathrm{SD}=0.004$ a.u., $n=25$ of 34 ); both were normally distributed. Responders from primed animals had significantly higher response magnitudes $\left(F_{(2,59)}=40,{ }^{\star * * *} p<0.0001\right.$, oneway ANOVA followed by Dunnett's post hoc test vs "primed responders": $q_{59}=8.4$, adjusted $p<0.0001$ for control; $q_{59}=8.4$,

$\leftarrow$

before intradermal fentanyl was not different from systemic pretreatment baselines $\left(t_{5}=0.41\right.$ $p=0.70$, for the vehicle-treated group and, $t_{5}=0.17 ; p=0.87$, for the fentanyl-treated group; paired Student's $t$ test). In the group previously treated with systemic vehicle, intradermal fentanyl did not induce changes in the mechanical nociceptive threshold. However, intradermal fentanyl-induced hyperalgesia $(0 \mathrm{IH})$ in the systemic fentanyl-treated group $\left(t_{10}=14\right.$, ${ }^{* * * *} p<0.0001$, when the hyperalgesia in the groups was compared, 30 min after intradermal fentanyl; unpaired Student's $t$ test; $n=6$ paws per group). 
adjusted $p<0.0001$ for "primed nonresponders"). Additionally, the fraction of responders $(9 / 34=26 \%)$ among neurons from primed rats was significantly greater than in the control group (0/28) (twosided Fisher's exact test, $p=0.003$ ). Thus, there are significant qualitative and quantitative differences in response to fentanyl, between cultured putative nociceptive small DRG neurons from opioid-naive and opioid primed animals. These findings provide proof of concept for our hypothesis that neuronal plasticity induced by administration of an analgesic dose of fentanyl, in vivo, persists in short term neuronal culture, as well as providing a model of neuroplasticity, "in a dish," and in particular, with $\mathrm{OIH}$ as one of its manifestations.

Because fentanyl is not a pure MOR agonist, to provide insight into the receptor at which fentanyl acts to induce enhanced $\mathrm{Ca}^{2+}$ responses in nociceptors cultured from primed animals, starting 10 min before recordings we incubated cells with the selective MOR antagonist CTOP ( $1 \mu \mathrm{M})$, followed by coadministration of CTOP with fentanyl. As a result of adding CTOP, no neurons were qualified as responders, with responses in all neurons from primed animals now forming a uniform distribution not significantly different from control or nonresponders (Fig. 4). These findings support the suggestion of a critical role of nociceptor MORs in the enhanced $\mathrm{Ca}^{2+}$ responses to fentanyl in nociceptors from primed rats. Administration of vehicle, instead of fentanyl, to primed cultured neurons, produced responses with magnitudes close to ones in the CTOP treated group (no statistically significant difference, $p=0.97$ ). And, no neurons qualified as responders, confirming that fentanyl was required to produce its MOR-mediated effects. Hence, enhanced $\mathrm{Ca}^{2+}$ responses in neurons from primed animals were not the result of an indirect effect, for instance from increased mechanical sensitivity of primed neurons to medium flow and switching solutions.

\section{Fentanyl increases excitability of sensory neurons from primed rats}

Although changes in fentanyl-induced calcium signaling is important for hyperalgesic priming (Araldi et al., 2018c), these findings do not answer the fundamental question, does fentanyl sensitize DRG neurons cultured from primed animals, similar to what likely happens in vivo, based on OIH observed in our behavioral experiments (Fig. $1 B$ )? To address this question we performed in vitro electrophysiological experiments to compare the effect of fentanyl on electrical excitability in sensory neurons from primed and control rats. Rheobase, the minimal sustained current required to generate an action potential (AP), was selected as a robust electrophysiological property reflecting neuronal electrical excitability (Hendrich et al., 2013; Duzhyy et al., 2015; Ferrari et al., 2018). Relative change in rheobase (as the percentage decrease) was used as a measure of the magnitude of sensitization (Ferrari et al., 2018). We previously demonstrated a

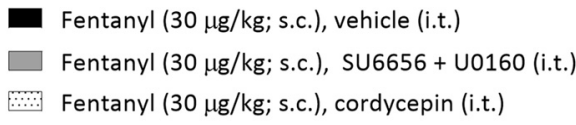

E

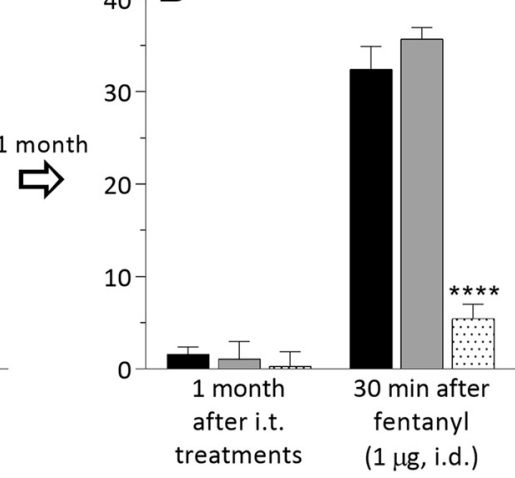

(1 $\mu$ g, i.d.)

$\begin{array}{cc}\text { after i.t. } & \text { fentanyl } \\ \text { treatments } & (1 \mu \mathrm{g}, \text { i.d. })\end{array}$ treated with fentanyl (30 $\mu \mathrm{g} / \mathrm{kg}$, s.c.) subcutaneously. Forty-eight hours later, vehicle $(20 \mu \mathrm{l})$, the combination of SU6656 $(10 \mu \mathrm{g} / 10 \mu \mathrm{l})+U 0126(10 \mu \mathrm{g} / 10 \mu \mathrm{l})$ or cordycepin $(4 \mu \mathrm{g} / 20 \mu \mathrm{l})$ was injected intrathecally, followed 10 min later by fentanyl $(1 \mu \mathrm{g} / 5 \mu \mathrm{l})$, injected intradermally, on the dorsum of the hindpaw.

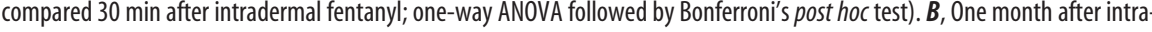
mechanical nociceptive threshold evaluated $30 \mathrm{~min}$ later. Although hyperalgesia induced by intradermal fentanyl was still re-

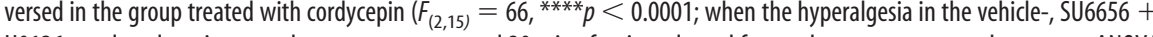
in fentanyl-primed rats is dependent on protein translation in the nociceptor, sharing a mechanism in common with type contribution of peptidergic (predominantly IB4 ${ }^{-}$) and IB4binding (predominantly nonpeptidergic) nociceptors, leading us to infer an important role of weakly IB4 ${ }^{+}$DRG neurons, which are peptidergic (Fang et al., 2006), to opioid-induced priming (Araldi et al., 2015, 2018a,c). We used in vitro IB4-labeling of live neurons undergoing electrophysiological recordings to separate small-diameter DRG neurons into three classes: strongly IB4 ${ }^{+}$ (nonpeptidergic), weakly IB4 ${ }^{+}$(peptidergic), and IB4 ${ }^{-}$(peptidergic) (Petruska et al., 2000; Fang et al., 2006; Woolf and Ma, 2007; Khomula et al., 2013, 2017). The effect of fentanyl (0.5 nM) on rheobase was then examined, comparing within and between classes of neurons from control and primed rats.

In neurons from opioid-naive rats, we found that fentanyl induced a significant decrease of rheobase in the class of strongly $\mathrm{IB}^{+}{ }^{+}$small-diameter DRG neurons $(21 \pm 7 \%, n=12)$, whereas in weakly IB4 ${ }^{+}$and IB4 ${ }^{-}$neurons, rheobase was not significantly different from baseline (the corresponding changes of rheobase were $7 \pm 9 \%, n=10$ and $2 \pm 7 \%, n=10$ ) (Fig. 5). This finding suggests a nociceptor subtype-dependent neuronal sensitization by fentanyl in sensory neurons from opioid-naive rats, but only in the strongly IB4 ${ }^{+}$, nonpeptidergic subtype.

The same experiments conducted in sensory neurons from primed rats revealed significant sensitization in all classes of small-diameter DRG neurons. Rheobase was decreased by $28 \pm$ $5 \%(n=10)$ in strongly IB $4^{+}, 30 \pm 6 \%(n=10)$ in weakly IB4 ${ }^{+}$ and $27 \pm 10 \%(n=10)$ in IB4 ${ }^{-}$small DRG neurons. Two-way ANOVA confirmed a statistically significant effect of group (i.e., priming in vivo versus naive animals; $F_{(1,56)}=17, p=$ $0.0001)$, but not IB4-binding class $\left(F_{(2,56)}=1.8, p=0.17\right)$ or 
A
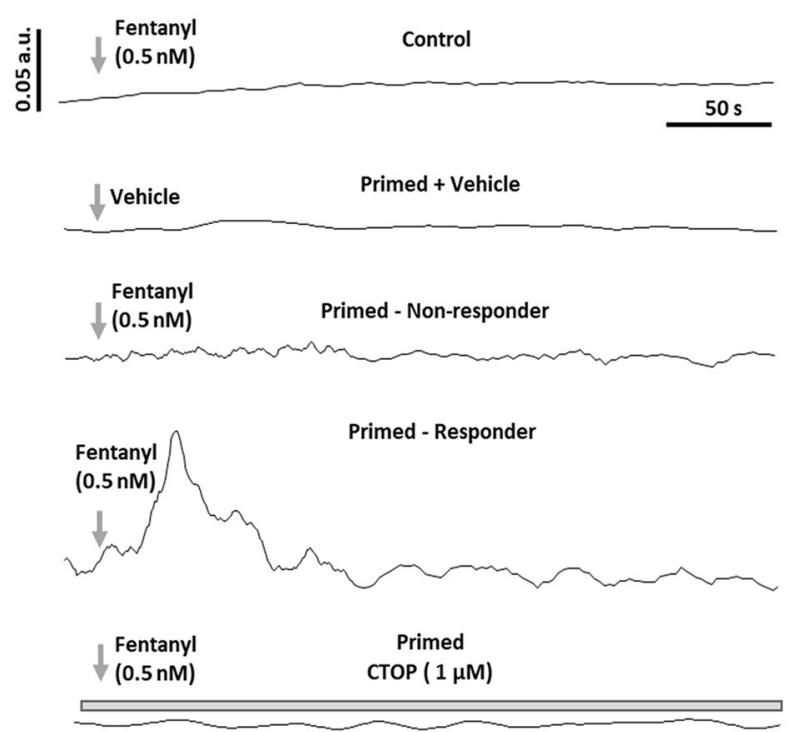

B

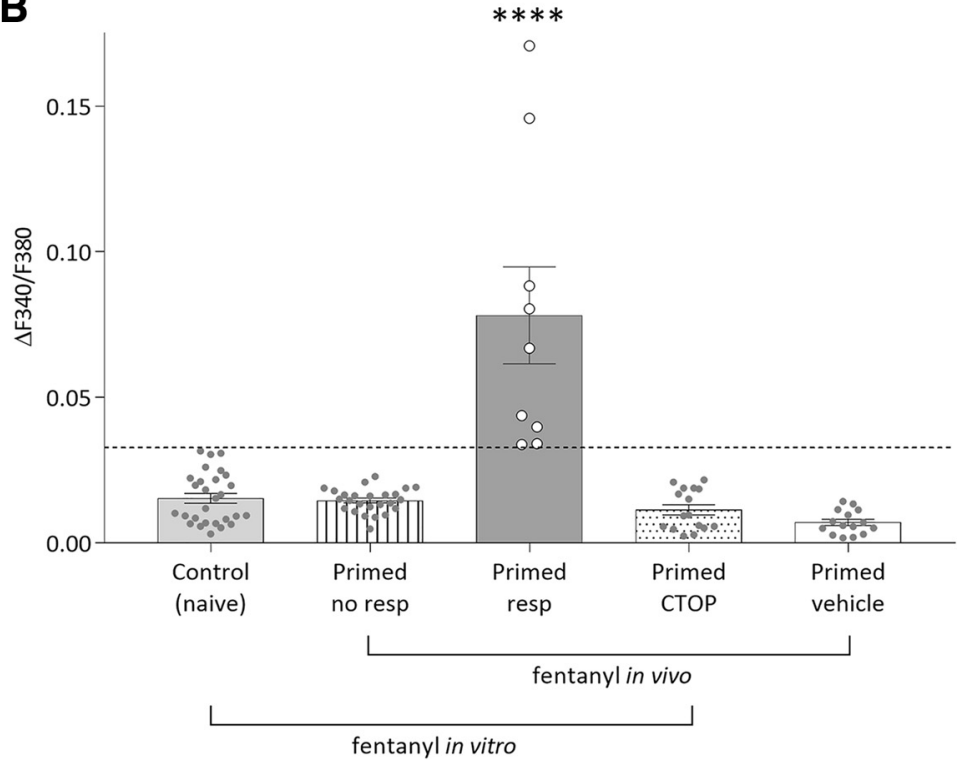

Figure 4. Fentanyl-induced $\mathrm{Ca}^{2+}$ signals in sensory neurons. Rats were primed in vivo by systemic administration of fentanyl ( $30 \mu \mathrm{g} / \mathrm{kg}$, s.c.) $3 \mathrm{~d}$ before the preparation of DRG neuron cultures. In vitro recordings were made after $24 \mathrm{~h}$ in culture. Only small DRG neurons (soma diameter $<30 \mu \mathrm{m}$; putative nociceptors) were considered for this analysis. $\boldsymbol{A}$, Illustrative traces for time course of $\left[\mathrm{Ca}^{2+}\right]_{\mathrm{i}}$ from each group, obtained by ratiometric calcium imaging with Fura- 2 dye and reported as F340/F380 fluorescence ratio. The vertical gray arrow depicts the start of fentanyl $(0.5 \mathrm{~nm})$ (or vehicle for vehicle group) administration (bath application). Fentanyl remained in the perfusion chamber during recordings. Gray horizontal bar above the trace for the Primed CTOP group indicates presence of selective MOR antagonist CTOP $(1 \mu \mathrm{M})$ in the recording chamber, starting 10 min before and continuing during fentanyl administration. $\boldsymbol{B}$, Bars and dots show pooled magnitudes, mean and individual responses correspondingly, of maximum increase of the " $\mathrm{F} 340 / \mathrm{F} 380$ " ratio during the 5 min administration of fentanyl ( $0.5 \mathrm{~nm}$ ) (or vehicle for "Primed, vehicle" group) compared with preadministration baseline. The distribution of the response magnitudes of cells from primed animals $(n=34)$ did not pass testing for normality and therefore was subdivided into two groups, responders (Primed resp, 9 of 34 neurons in the group, 26\%) and nonresponders (Primed no resp, 25 of 34 neurons in the group, 74\%), based on the magnitude of their response. A response magnitude of 0.032 was set as the threshold, based on the [mean $+2 \times$ SD] in the control group (shown as dash line). Both groups demonstrated normality after splitting into responders and nonresponders. Enhanced $\mathrm{Ca}^{2+}$ responses in cultured neurons from primed animals were dependent on activation of MOR as revealed by significant attenuation when CTOP $(1 \mu \mathrm{M})$ was coadministered with fentanyl (Primed CTOP bar). One-way ANOVA with Dunnet's post hoc test revealed a significant difference between primed responders and all other groups $\left({ }^{* * * *} p<0.0001 ; F_{(4,88)}=33\right)$. Number of cells in experimental groups: control, $n=28$; primed vehicle, $n=15$; primed CTOP, $n=16$; primed responders, $n=9$; primed nonresponders, $n=25$. their interaction $\left(F_{(2,56)}=2.3, p=\right.$ $0.11)$. Sidak's post hoc test demonstrated a statistically significant difference between primed and control groups, but only for IB4 ${ }^{-}\left(t_{56}=2.8\right.$, adjusted $p=$ $0.02)$ and weakly IB4 ${ }^{+}\left(t_{56}=3.6\right.$, adjusted $p=0.002$ ) neurons, as they were not sensitized in control but markedly sensitized in neurons from the primed group of rats. No significant difference was revealed for strongly IB4 ${ }^{+}$neurons $\left(\mathrm{t}_{56}=0.74\right.$, adjusted $\left.p=0.85\right)$, suggesting they were not additionally sensitized after in vivo priming.

Comparison between neuronal classes within groups by Sidak's post hoc test confirmed a significant difference between strongly IB $4^{+}$and weakly IB4 ${ }^{+}$neurons under control conditions $\left(\mathrm{t}_{56}=2.7\right.$, adjusted $p=0.03$ ). In contrast, there was no significant difference between different IB4-binding classes under primed conditions. After merging all classes into a single primed group, average decrease of rheobase was $28 \pm 4 \%(n=30)$. Because the combined group had a distribution significantly different from Gaussian (D'Agostino and Pearson normality test, $\left.K_{2}=6.5, p=0.04\right)$, we used an approach similar to our data analysis for the calcium imaging data; the combined primed group was split into two nonoverlapping groups, nonresponders (below threshold $20 \%$; range from -10 to $18 \%$, average $8 \pm$ $2 \%, n=12$ of $30,40 \%$ of primed neurons) and responders (above the threshold; range from 23 to $64 \%$, average $38 \pm 3 \%$, $n=18$ of $30,60 \%$ of primed neurons) (Fig. 6). Rhe fraction of electrophysiologically defined responders was higher than the fraction of responders in calcium signaling (26\%, 9 of 34) (two-sided Fisher's exact test, $p=0.01$ ).

\section{In vivo reversal of $\mathrm{OIH}$ reverses nociceptor fentanyl-induced hyperexcitability}

Our behavioral experiments demonstrated that intradermal fentanyl failed to induce hyperalgesia $(\mathrm{OIH})$ in rats treated in vivo with intrathecal cordycepin, administered after systemic fentanyl, supporting the suggestion of in vivo reversal of the neuroplasticity responsible for OIH. To validate the proposed model of nociceptor neuroplasticity "in a dish," we addressed if changes in neuronal calcium signaling and electrical excitability, which were found in vitro and attributed to the neuroplasticity induced by fentanyl in vivo, were eliminated in DRG neurons cultured from rats subjected to in vivo reversal of $\mathrm{OIH}$ by cordycepin (Fig. 3). 


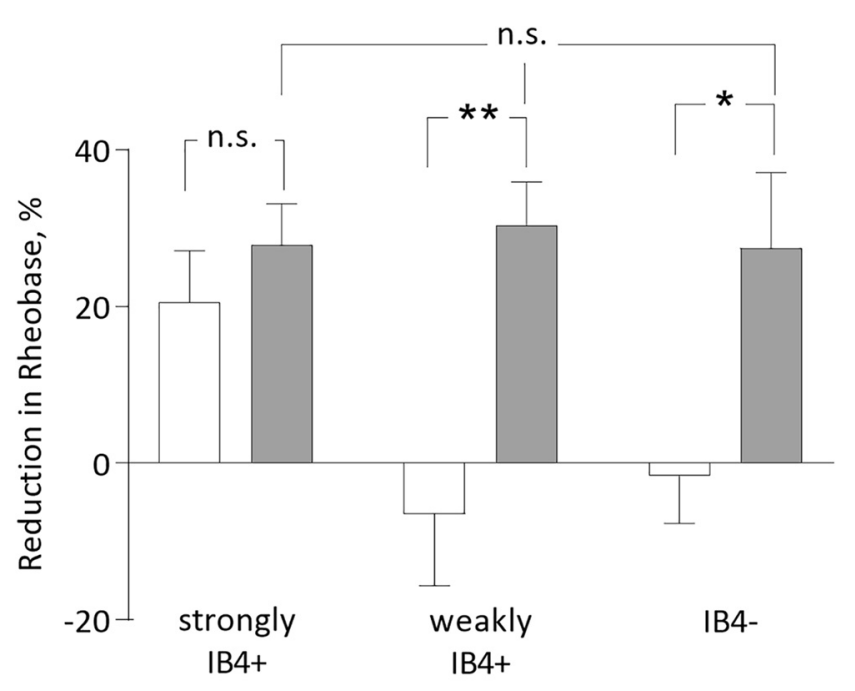

Control (opiod naive)

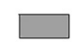

Primed in vivo by fentanyl

Figure 5. Fentanyl-induced sensitization of primed sensory neurons. Rats were primed by the systemic administration of fentanyl ( $30 \mu \mathrm{g} / \mathrm{kg}$, s.c.) $3 \mathrm{~d}$ before preparing neuronal cultures; recordings were made after $24 \mathrm{~h}$ in culture. Bars show pooled magnitudes of decrease in rheobase, relative to preadministration baseline, 5 min after fentanyl $(0.5 \mathrm{~nm})$ was added to the perfusion chamber. Small DRG neurons from fentanyl-primed and control (opioid-naive) rats, depicted by the white and gray bars, correspondingly, were separated by IB4-binding intensity into strongly IB4 ${ }^{+}$, weakly IB4 ${ }^{+}$and IB4 ${ }^{-}$classes. In sensory neurons from opioid-naive animals, a significant fentanyl-induced decrease of rheobase was detected in strongly $\mathrm{IB}^{+}{ }^{+}$, but not in weakly IB4 ${ }^{+}$and IB4 ${ }^{-}$neurons. In contrast, in sensory neurons from primed rats, fentanyl decreased rheobase in all three classes of nociceptors, with no significant difference in magnitude between classes. Two-way ANOVA confirmed a statistically significant effect of group (i.e., priming in vivo versus naive animals; $F_{(1,56)}=17, p=0.0001$ ), but not IB4-binding class $\left(F_{(2,56)}=1.8, p=0.17\right)$ or their interaction $\left(F_{(2,56)}=2.3, p=0.11\right)$. Sidak's post hoc test demonstrated a statistically significant difference between primed and control groups for IB4 $\left(\mathrm{t}_{56}=2.8,{ }^{*}\right.$ adjusted $\left.p=0.02\right)$ and weakly IB4 ${ }^{+}\left(\mathrm{t}_{56}=3.6{ }^{*}{ }^{*}\right.$ adjusted $\left.p=0.002\right)$, but not for strongly IB4 ${ }^{+}$neurons ( $\mathrm{t}_{56}=0.74$, adjusted $p=0.85$ ). Number of cells in experimental groups: strongly IB ${ }^{+}$in control, $n=12$; the other 5 bars, $n=10$. n.s., statistically not significant $(p>0.05)$.

Analysis of fentanyl-induced $\left[\mathrm{Ca}^{2+}\right]_{\mathrm{i}}$ responses, in cultured small DRG neurons from rats that had been treated with intrathecal cordycepin, after a systemic analgesic dose of fentanyl, in vivo, in the same way as described in Figure 3 (denoted as reversal group), was performed following the same protocol as established for comparison of control and fentanyl-primed groups of rats (see Fig. 4 legend for details). Only 2 of 33 neurons (6\%) from the reversal group qualified as responders (Fig. 7A). Comparison with fractions of responders in control and primed groups revealed a statistically significant difference $\left(\chi^{2}\right.$ test for 3 groups: $\left.p=0.0025, \chi^{2}=12, \mathrm{df}=2\right)$. The fraction of responders in the reversal group was lower than in the primed group, and not different from control groups (two-sided Fisher's exact test, $p=$ 0.044 for reversal $v s$ primed groups, and $p=0.50$ for reversal $v s$ control groups). These findings support the suggestion that reversal of $\mathrm{OIH}$ in vivo significantly diminishes changes in calcium signaling produced by in vitro fentanyl.

Next, we evaluated in vitro the effect of fentanyl on electrical excitability in sensory neurons from the reversal group to compare with changes in excitability attributed to the effect of priming. Since the significant in vitro fentanyl-induced increase in excitability (decrease in rheobase) was observed only in weakly $\mathrm{IB}^{+}{ }^{+}$and IB4 ${ }^{-}$neurons from in vivo fentanyl-primed rats, we considered only neurons from these two classes for the analysis of the effect of reversal of OIH in vivo on the in vitro electrophysiological properties of cultured nociceptors. The sensitization effect of fentanyl in vitro was abolished only in weakly IB4 ${ }^{+}$neurons (ones involved in type I hyperalgesic priming; Joseph and Levine, 2010 b) from the reversal group (Fig. $7 B$ ), where fentanyl did not produce any significant change in rheobase compared with baseline (similarly to what was observed in unprimed control conditions). In contrast, fentanyl still produced a significant decrease in rheobase in $\mathrm{IB}^{-}$neurons from the reversal group, with magnitude similar to that in the primed group (Fig. $7 B$ ). Thus, reversal of OIH by in vivo cordycepin eliminated in vitro electrophysiological changes attributed to neuroplasticity induced by systemic fentanyl in weakly IB4 ${ }^{+}$, but not in IB4 ${ }^{-}$neurons. These findings support the suggestion that the development of $\mathrm{OIH}$ in fentanyl-primed animals occurs in the weakly IB4 ${ }^{+}$ nociceptors.

In summary, we have demonstrated, in vivo, the existence of long-lasting nociceptor neuroplasticity induced by a single systemic administration of an analgesic dose of fentanyl. This neuroplasticity, which involves changes in nociceptor function, is responsible for hyperalgesia $(\mathrm{OIH})$ as demonstrated by the subsequent intradermal exposure to fentanyl, bearing features of hyperalgesic priming. Additionally, for the first time, we have provided an in vitro model for studying opioid-induced nociceptor neuroplasticity, with OIH as one of its "symptoms." Using this model, we have provided evidence for the existence of specific changes in calcium signaling and electrophysiological properties of nociceptors, in their response to fentanyl, which correlate well with susceptibility to $\mathrm{OIH}$ and reversal of this susceptibility by cordycepin. As well, this combination of behavioral and in vitro cellular approaches allowed us to provide direct evidence for a role of weakly IB4 ${ }^{+}$nociceptors in OIH under conditions of fentanyl-induced neuroplasticity.

\section{Discussion}

In the present study, we induced nociceptor neuroplasticity, in vivo, by systemic administration of a single high-analgesic dose of fentanyl. Two days later, when fentanyl was injected intradermally, it produced mechanical hyperalgesia $(\mathrm{OIH})$ not observed in opioid-naive rats (Fig. 1B). A systemic effect of intradermal fentanyl was excluded by the absence of hyperalgesia in the contralateral hindpaw. In our previous studies, hyperalgesic priming was detected whenever OIH was present (Araldi et al., 2015, 2017, 2018a,b,c; Ferrari et al., 2019), leading us to propose that they share underlying mechanisms.

Two forms of hyperalgesic priming have been reported. Type I develops after local administration of pronociceptive mediators, activation of protein kinase $\mathrm{C} \varepsilon(\mathrm{PKC} \varepsilon)$, and ryanodineinduced release of calcium from the endoplasmic reticulum (Parada et al., 2003a; Dina et al., 2008; Reichling and Levine, 2009; Ferrari et al., 2010, 2015b; Alvarez et al., 2014). Type I priming is maintained by protein translation in axons and dendrites (i.e., reversed by local administration of cordycepin or rapamycin) (Ferrari et al., 2013a,b, 2014, 2015b), and occurs in IB4 ${ }^{+}$, but not in $\mathrm{IB}^{-}$(peptidergic) nociceptors (Joseph and Levine, 2010b). Type II priming, induced by administration of the selective MOR agonist DAMGO, at the peripheral terminal of the nociceptor, relies on different mechanisms, including: MOR signaling in IB4 ${ }^{-}$(peptidergic) nociceptors (Araldi et al., 2015) and reversal by the combination of a Src and MAPK inhibitor (Araldi et al., 2017, 2018a). Calcium signaling via ryanodine receptors has, however, been implicated in both fentanyl-induced 


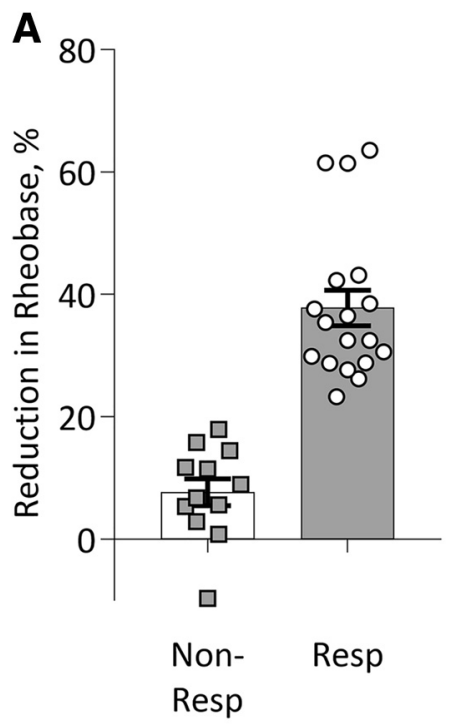

B

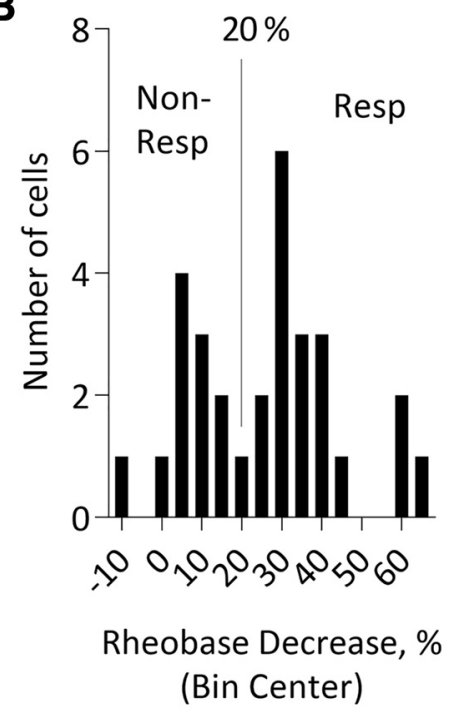

Figure 6. Fentanyl-induced decrease in rheobase in primed sensory neurons. $A$, Bars and dots show pooled magnitudes, mean and individual responses, respectively, of decrease in rheobase during the 5 min administration of fentanyl $(0.5 \mathrm{~nm})$ relative to preadministration baseline in all sensory neurons (regardless of IB4-binding status) from primed animals. Neuronal responses were split into nonresponders and responders based on the magnitude of the fentanyl-induced decrease in rheobase with threshold selected at $20 \%$ (based on the visual gap in the distribution shown in $\boldsymbol{B}$ ). Nonresponders (below the threshold; noted as NonResp and depicted by white bar with gray squares) constituted $40 \%$ of neurons ( $n=12$ of 30 ), had average sensitization of $8 \pm 2 \%$, ranging from -10 to $+18 \%$. Responders (above the threshold; noted as Resp and depicted by gray bar with white circles) constituted $60 \%$ of neurons ( $n=18$ of 30 ), had average sensitization of $38 \pm 3 \%$, ranging from 23 to $64 \%$. Responders and nonresponders were found in all three IB4-binding classes of neurons cultured from primed animals.

type I and type II priming (Araldi et al., 2018c). MOR-dependent $\mathrm{OIH}$ and type I priming are induced in the peripheral nociceptor terminal by local administration of a low dose of fentanyl (intradermal or intrathecal) (Araldi et al., 2018c). Also, type I priming develops in the peripheral nociceptor terminal after systemic administration of high dose fentanyl (Araldi et al., 2018c). Therefore, we tested the hypothesis that OIH produced by an analgesic dose of systemic fentanyl, is mediated by the same mechanism that mediates type I priming.

Cordycepin, which reverses type I priming (Ferrari et al., 2013b), permanently reversed OIH produced by intradermal fentanyl in rats primed with systemic fentanyl (Fig. 3). Thus, OIH produced by fentanyl shares a maintenance mechanism with type I priming. While inhibition of protein translation can account for the permanent reversal of OIH (Fig. 3B), the onset of reversal could be due, in part to its ability to inhibit voltage gated sodium channels (Liu et al., 2017). While sharing maintenance mechanisms with type I priming, induction and expression of hyperalgesic priming and $\mathrm{OIH}$ rely, at least in part, on different mechanisms, and are expressed in different populations of nociceptors (Araldi et al., 2015, 2018a,c).

After exposure to fentanyl in vitro, in one-fourth of all putative nociceptors from the primed rats, we observed a higher peak in $\left[\mathrm{Ca}^{2+}\right]_{\mathrm{i}}$ (responders) than all responses in control nociceptors, which was similar in magnitude to the other $74 \%$ of neurons from primed rats (nonresponders; Fig. 4). These results correlate with $\mathrm{OIH}$ in vivo, supporting the role of calcium signaling in $\mathrm{OIH}$. Absence of responders after coadministration of the selective MOR antagonist CTOP with fentanyl, provides support for the action of fentanyl at MORs to induce calcium signals in responders (Fig. 4). This is also supported by our previous finding that $\mathrm{OIH}$, induced by low dose fentanyl, and priming induced by low and high dose fentanyl, are dependent on both MOR and calcium release from endoplasmic reticulum (Araldi et al., 2018c). The fraction of responders, $26 \%$ of small-diameter DRG neurons, in our calcium imaging experiments, is compatible with the reported fraction of DRG neurons, of all sizes, expressing MORs, which ranges from $21 \%$ to $39 \%$ (Ji et al., 1995; Schmidt et al., 2013; Bardoni et al., 2014; Corder et al., 2017).

A versatile intracellular second messenger, $\mathrm{Ca}^{2+}$ is known to modulate neuronal function, producing both fast and slow/delayed changes in excitability (Hagenston and Simonetti, 2014; Zhang et al., 2014; Bernard-Marissal et al., 2018; Luarte et al., 2018; Bandura and Feng, 2019). However, since an increase in $\left[\mathrm{Ca}^{2+}\right]_{i}$ in response to fentanyl is not a direct measure of nociceptor sensitization, we also studied changes in electrical excitability, in vitro. Also, while our previous in vivo studies involved use of IB4- and SSPsaporin, neurotoxins for IB4-binding and peptidergic populations of neurons (Araldi et al., 2018c), the effect of both saporins on an overlapping class of nociceptors, weakly $\mathrm{IB}^{+}{ }^{+}$and peptidergic, complicates the interpretation of in vivo results. In contrast, the ability to identify weakly IB4 ${ }^{+}$, strongly IB $4^{+}$, and IB4 ${ }^{-}$nociceptors immunohistochemically, in vitro, provides a unique opportunity to investigate nociceptor class-specific actions of fentanyl, especially for the weakly IB4 ${ }^{+}$nociceptors.

While fentanyl sensitized some DRG neurons from control rats, this only occurred in the strongly IB $4^{+}$small-diameter DRG neurons. MOR is expressed predominantly in peptidergic/ $\mathrm{TRPV}^{+}{ }^{+}$(almost all SP ${ }^{+}$and/or TRPV1 ${ }^{+}$DRG neurons express MOR; among small-diameter MOR + DRG neurons $85 \%$ are $\mathrm{TRPV}^{+}{ }^{+}$and only $8 \% \mathrm{IB}^{+}{ }^{+}$) (Scherrer et al., 2009; Joseph and Levine, 2010a; Bardoni et al., 2014; Corder et al., 2017), supporting the suggestion that the observed sensitization of strongly $\mathrm{IB}^{+}{ }^{+}$nociceptors is not MOR-mediated, and therefore not associated with MOR-dependent $\mathrm{OIH}$ and fentanyl-induced priming (Araldi et al., 2018c; Ferrari et al., 2019). In contrast, priming of animals in vivo likely affected peptidergic sensory neurons (IB4 ${ }^{-}$ and weakly IB4 ${ }^{+}$) (Fang et al., 2006), whereas strongly IB4 ${ }^{+}$, nonpeptidergic, sensory neurons were not further sensitized (Fig. 5). Peptidergic nociceptors have been implicated in type I and type II priming, in behavioral experiments (Araldi et al., 2015, 2018a,c). Therefore, we suggest that IB4- and/or weakly $\mathrm{IB} 4{ }^{+}$nociceptors underlie neuroplasticity mediating OIH.

Similar to our calcium signaling results, primed neurons can be nonoverlappingly separated into responders and nonresponders based on magnitude of their decrease in rheobase. The fraction of electrophysiologically defined responders (60\%; Fig. 6) was approximately twice the fraction with enhanced calcium signal (26\%; Fig. 4). This finding supports the suggestion that while sensitization could occur in neurons that did not exhibit a detectable increase in $\left[\mathrm{Ca}^{2+}\right]_{\mathrm{i}}$ in response to fentanyl (calcium nonresponders), there is currently no clear link between altered calcium signaling and acute sensitization produced by fentanyl, 
A

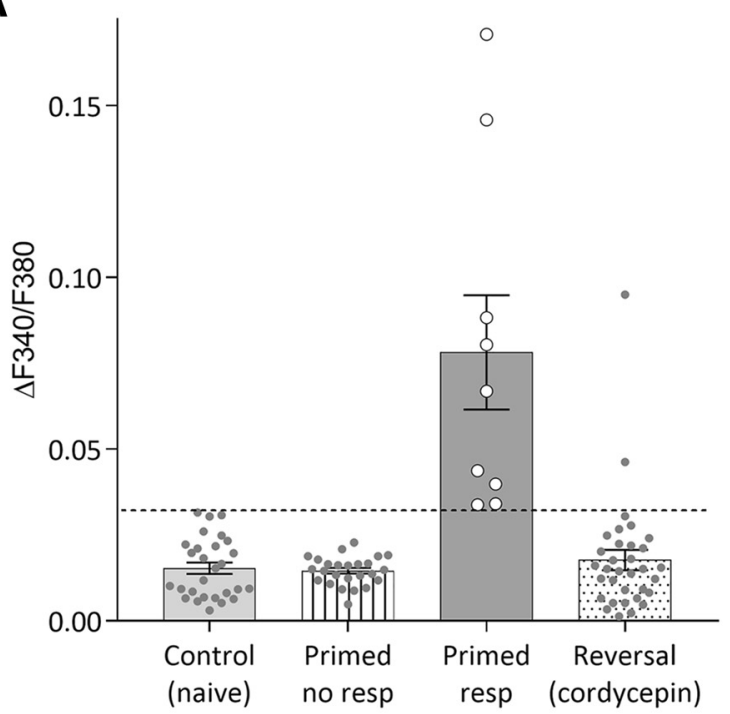

B

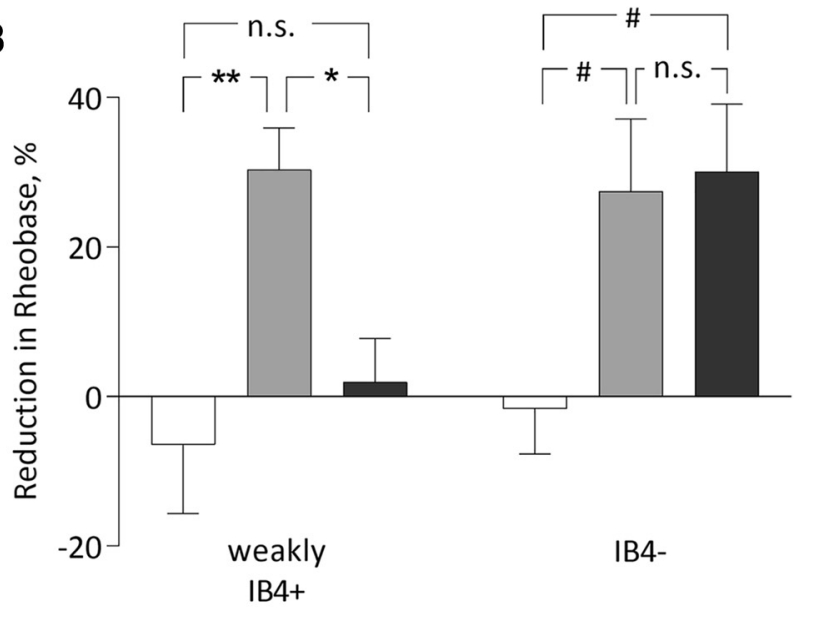

\section{Control $\square$ Primed \\ Reversal}

Figure 7. Effect of fentanyl on $\left[\mathrm{Ca}^{2+}\right]_{i}$ and rheobase in sensory neurons from cordycepintreated primed rats. Rats were treated with systemic fentanyl ( $30 \mu \mathrm{g} / \mathrm{kg}$, s.c.) and, $2 \mathrm{~d}$ later, cordycepin $(4 \mu \mathrm{g} / 20 \mu$ l) was injected intrathecally (in the same way as described in Fig. 3). As shown in behavioral experiments, this protocol eliminates the ability of intradermal fentanyl to induce hyperalgesia $(\mathrm{OIH})$. The next day neuronal cultures were prepared; rats used for culture preparation did not receive intradermal fentanyl. The effect of fentanyl ( $0.5 \mathrm{nM})$ on calcium signaling $(\boldsymbol{A})$ and electrical excitability $(\boldsymbol{B})$ was examined in the same way as described in Figures 4 and 5 , correspondingly, starting $1 \mathrm{~d}$ after preparation of neuronal culture. These results constitute the reversal groups in $\boldsymbol{A}$ and $\boldsymbol{B}$. $\boldsymbol{A}$, Bars and dots show pooled magnitudes, mean and individual responses correspondingly, in small DRG neurons from the reversal group (most right group) along with data for control and primed responders and nonresponders, which were repeated from Figure $4 B$ for the purpose of comparison. The same threshold $(0.032$ a.u. as in Fig. $4 B$; shown as dash line) was used to split neurons from the reversal group into responders $(n=2)$ and nonresponders $(n=31)$. Fractions of responders were significantly different between groups ( $\chi^{2 \text { test }}$ for 3 groups: $p=0.0025, \chi^{2}=12$, df $=2$ ). Effect of $\mathrm{OlH}$ reversal protocol was significant, compared with the primed group (two-sided Fisher's exact test, $p=0.044$ ), supporting the suggestion that reversal of $01 \mathrm{H}$ in vivo significantly diminishes changes in calcium signaling produced by in vitro fentanyl. $\boldsymbol{B}$, Bars show pooled magnitudes of decrease in rheobase, relative to preadministration baseline, 5 min after fentanyl $(0.5 \mathrm{~nm})$ was added to the perfusion chamber. Only weakly IB4 ${ }^{+}$and IB4 ${ }^{-}$neurons were considered for this analysis, as those were affected by fentanyl-induced priming (Fig. 5). Neurons from primed and control (opioid-naive) rats, depicted by the white and gray bars, correspondingly, were transferred from Figure 5 for the purpose of comparison. Sensitization effect of in vitro fentanyl was abolished only in weakly IB4 ${ }^{+}$neurons from the reversal group, whereas decrease in in vitro. Of note, in this regard, this sensitization can be mediated by PKC $\varepsilon$, a calcium-independent kinase (Khasar et al., 1999; Aley et al., 2000; Parada et al., 2005; Reichling and Levine, 2009; Ferrari et al., 2015a) which is a MOR second messenger (Chu et al., $2010)$. At the same time, the fraction of responders, in excitability ( $60 \%$ of small-diameter DRG neurons), may be greater than the upper limit of MOR-expressing DRG neurons (39\% of DRG neurons of all sizes). This could be due to a contribution of a MORindependent action of fentanyl on nociceptors in their acute sensitization, in vitro. One such target might be TLR4 (Watkins et al., 2009; Stevens et al., 2013; Okudaira et al., 2016; Sun et al., 2019), activation of which produces OIH (unpublished observation). Redistribution and enhanced expression of MOR as part of neuroplasticity, is another possibility, as it has been shown to occur after inflammation and nerve injury (Ji et al., 1995; Kolesnikov et al., 2007; Schmidt et al., 2013).

Finally, in parallel with the reversal of OIH by cordycepin in vivo (Fig. 3), in weakly IB4 ${ }^{+}$neurons, the sensitization effect of fentanyl was also reversed (Fig. 7). This finding supports the suggestion that it is the weakly $\mathrm{IB}^{+}{ }^{+}$nociceptors that underlie $\mathrm{OIH}$.

That not all patients who receive opioids develop OIH (Suzan et al., 2013) may be related to differences in levels of stress as well as genetic and/or developmental differences in stress axis responsiveness. OIH was found to be strongest in patients with the met/met catechol-O-methyltransferase polymorphism, which is responsible for markedly greater stress-induced increases in plasma levels of stress axis mediators (Jabbi et al., 2007; Jensen et al., 2009). Patients with preoperative stress are more vulnerable to postoperative pain (Munafo and Stevenson, 2001) and, stress exacerbates OIH (Edwards et al., 2011, 2016; Laboureyras et al., 2014). Stress also induces hyperalgesic priming (Khasar et al., 2009; Green et al., 2011).

In summary, we have developed an in vitro model of $\mathrm{OIH}$ to investigate cellular and molecular mechanisms underlying neuroplasticity, induced by opioids in vivo at the level of the nociceptor. Our preclinical OIH model might have clinical relevance because, although high-dose fentanyl is often given during surgery, the lower doses administered postoperatively can be associated with OIH (Chia et al., 1999; Yildirim et al., 2014; Yi and Pryzbylkowski, 2015; Kim et al., 2018). Our findings provide support for the hypothesis that an analgesic dose of fentanyl in vivo induces long-lasting nociceptor neuroplasticity, which persists in culture and provides evidence for the important role of nociceptor MOR-mediated calcium signaling and peripheral protein translation in the weakly IB4-binding population of nociceptors in $\mathrm{OIH}$.

\section{$\leftarrow$}

rheobase in IB4 ${ }^{-}$neurons from the reversal group remained unattenuated, compared with the primed group (two-way ANOVA: $F_{(2,46)}=9.9, p=0.0003$ for the effect of primed vs reversal condition; Holm-Sidak's post hoc test: comparison within weakly IB4 ${ }^{+}$neurons: $t_{46}=3.5,{ }^{* *}$ adjusted $p=0.003$ for control vs primed; $t_{46}=0.70$, adjusted $p=0.49$ for control vs reversal; $t_{46}=2.3{ }^{*}$ adjusted $p=0.047$ for primed vs reversal; comparison within IB4 ${ }^{-}$neurons: $t_{46}=$ 2.8, \# adjusted $p=0.025$ for control vs primed; $t_{46}=2.6$, \# adjusted $p=0.025$ for control vs reversal; $t_{46}=0.22$, adjusted $p=0.83$ for primed vs reversal). Thus, cordycepin-induced reversal of $0 \mathrm{IH}$ in vivo eliminated in vitro electrophysiological changes attributed to neuroplas ticity induced by systemic fentanyl, only in weakly IB4 ${ }^{+}$. Number of cells in experimental groups in $\boldsymbol{A}$ : control, $n=28$; primed responders, $n=9$ and primed nonresponders $n=25$, reversal $n=33$; in $\boldsymbol{B}$ : control and primed groups, $n=10$ per IB4-binding class; reversal groups, $n=6$ per IB4-binding class. n.S., statistically not significant $(p>0.05)$. 


\section{References}

Aley KO, Messing RO, Mochly-Rosen D, Levine JD (2000) Chronic hypersensitivity for inflammatory nociceptor sensitization mediated by the epsilon isozyme of protein kinase C. J Neurosci 20:4680-4685.

Alvarez P, Green PG, Levine JD (2014) Role for monocyte chemoattractant protein-1 in the induction of chronic muscle pain in the rat. Pain 155:1161-1167.

Andersson HI, Ejlertsson G, Leden I, Rosenberg C (1993) Chronic pain in a geographically defined general population: studies of differences in age, gender, social class, and pain localization. Clin J Pain 9:174-182.

Angst MS, Clark JD (2006) Opioid-induced hyperalgesia: a qualitative systematic review. Anesthesiology 104:570-587.

Araldi D, Ferrari LF, Levine JD (2015) Repeated mu-opioid exposure induces a novel form of the hyperalgesic priming model for transition to chronic pain. J Neurosci 35:12502-12517.

Araldi D, Ferrari LF, Levine JD (2017) Hyperalgesic priming (type II) induced by repeated opioid exposure: maintenance mechanisms. Pain 158:1204-1216.

Araldi D, Ferrari LF, Levine JD (2018a) Role of GPCR (mu-opioid)receptor tyrosine kinase (epidermal growth factor) crosstalk in opioidinduced hyperalgesic priming (type II). Pain 159:864-875.

Araldi D, Ferrari LF, Levine JD (2018b) Mu-opioid receptor (MOR) biased agonists induce biphasic dose-dependent hyperalgesia and analgesia, and hyperalgesic priming in the rat. Neuroscience 394:60-71.

Araldi D, Khomula EV, Ferrari LF, Levine JD (2018c) Fentanyl induces rapid onset hyperalgesic priming: type I at peripheral and type II at central nociceptor terminals. J Neurosci 38:2226-2245.

Araldi D, Bogen O, Green PG, Levine JD (2019) Role of nociceptor Toll-like Receptor 4 (TLR4) in opioid-induced hyperalgesia and hyperalgesic priming. J Neurosci. Advance online publication. Retrieved June 17, 2019. doi:10.1523/JNEUROSCI.0966-19.2019.

Bandura J, Feng ZP (2019) Current understanding of the role of neuronal calcium sensor 1 in neurological disorders. Mol Neurobiol. Advance online publication. Retrieved February 4, 2019. doi:10.1007/s12035-0191497-2.

Bardoni R, Tawfik VL, Wang D, Francois A, Solorzano C, Shuster SA, Choudhury P, Betelli C, Cassidy C, Smith K, de Nooij JC, Mennicken F, O’Donnell D, Kieffer BL, Woodbury CJ, Basbaum AI, MacDermott AB, Scherrer G (2014) Delta opioid receptors presynaptically regulate cutaneous mechanosensory neuron input to the spinal cord dorsal horn. Neuron 81:1443.

Bernard-Marissal N, Chrast R, Schneider BL (2018) Endoplasmic reticulum and mitochondria in diseases of motor and sensory neurons: a broken relationship? Cell Death Dis 9:333.

Berridge MJ, Lipp P, Bootman MD (2000) The versatility and universality of calcium signalling. Nat Rev Mol Cell Biol 1:11-21.

Bogen O, Alessandri-Haber N, Chu C, Gear RW, Levine JD (2012) Generation of a pain memory in the primary afferent nociceptor triggered by PKCepsilon activation of CPEB. J Neurosci 32:2018-2026.

Carullo V, Fitz-James I, Delphin E (2015) Opioid-induced hyperalgesia: a diagnostic dilemma. J Pain Palliat Care Pharmacother 29:378-384.

Celerier E, Rivat C, Jun Y, Laulin JP, Larcher A, Reynier P, Simonnet G (2000) Long-lasting hyperalgesia induced by fentanyl in rats: preventive effect of ketamine. Anesthesiology 92:465-472.

Chang L, Ye F, Luo Q, Wang Z, Wang Y, Xia Z, Shu H (2018) Effects of three forms of local anesthesia on perioperative fentanyl-induced hyperalgesia. Biosci Trends 12:177-184.

Chia YY, Liu K, Wang JJ, Kuo MC, Ho ST (1999) Intraoperative high dose fentanyl induces postoperative fentanyl tolerance. Can J Anaesth 46:872877.

Chizhmakov I, Kulyk V, Khasabova I, Khasabov S, Simone D, Bakalkin G, Gordienko D, Verkhratsky A, Krishtal O (2015) Molecular mechanism for opioid dichotomy: bidirectional effect of mu-opioid receptors on P2X(3) receptor currents in rat sensory neurones. Purinergic Signal 11: $171-181$.

Chu J, Zheng H, Zhang Y, Loh HH, Law PY (2010) Agonist-dependent mu-opioid receptor signaling can lead to heterologous desensitization. Cell Signal 22:684-696.

Chu LF, Clark DJ, Angst MS (2006) Opioid tolerance and hyperalgesia in chronic pain patients after one month of oral morphine therapy: a preliminary prospective study. J Pain 7:43-48.
Cohen LB, Keynes RD, Hille B (1968) Light scattering and birefringence changes during nerve activity. Nature 218:438-441.

Compton P, Charuvastra VC, Ling W (2001) Pain intolerance in opioidmaintained former opiate addicts: effect of long-acting maintenance agent. Drug Alcohol Depend 63:139-146.

Compton P, Canamar CP, Hillhouse M, Ling W (2012) Hyperalgesia in heroin dependent patients and the effects of opioid substitution therapy. J Pain 13:401-409.

Corder G, Tawfik VL, Wang D, Sypek EI, Low SA, Dickinson JR, Sotoudeh C, Clark JD, Barres BA, Bohlen CJ, Scherrer G (2017) Loss of mu opioid receptor signaling in nociceptors, but not microglia, abrogates morphine tolerance without disrupting analgesia. Nat Med 23:164-173.

Crofford LJ (2010) Adverse effects of chronic opioid therapy for chronic musculoskeletal pain. Nat Rev Rheumatol 6:191-197.

Dina OA, Green PG, Levine JD (2008) Role of interleukin-6 in chronic muscle hyperalgesic priming. Neuroscience 152:521-525.

Duzhyy DE, Viatchenko-Karpinski VY, Khomula EV, Voitenko NV, Belan PV (2015) Upregulation of T-type Ca2 + channels in long-term diabetes determines increased excitability of a specific type of capsaicin-insensitive DRG neurons. Mol Pain 11:29.

Edwards RR, Wasan AD, Michna E, Greenbaum S, Ross E, Jamison RN (2011) Elevated pain sensitivity in chronic pain patients at risk for opioid misuse. J Pain 12:953-963.

Edwards RR, Dolman AJ, Michna E, Katz JN, Nedelikovic SS, Janfaza D, Isaac Z, Martel MO, Jamison RN, Wasan AD (2016) Changes in pain sensitivity and pain modulation during oral opioid treatment: the impact of negative affect. Pain Med 17:1882-1891.

Eisenberg E, Suzan E, Pud D (2015) Opioid-induced hyperalgesia (OIH): a real clinical problem or just an experimental phenomenon? J Pain Symptom Manage 49:632-636.

Fang X, Djouhri L, McMullan S, Berry C, Waxman SG, Okuse K, Lawson SN (2006) Intense isolectin-B4 binding in rat dorsal root ganglion neurons distinguishes $\mathrm{C}$-fiber nociceptors with broad action potentials and high Nav1.9 expression. J Neurosci 26:7281-7292.

Ferrari LF, Levine JD (2015) Plasma membrane mechanisms in a preclinical rat model of chronic pain. J Pain 16:60-66.

Ferrari LF, Bogen O, Levine JD (2010) Nociceptor subpopulations involved in hyperalgesic priming. Neuroscience 165:896-901.

Ferrari LF, Bogen O, Levine JD (2013a) Role of nociceptor alphaCaMKII in transition from acute to chronic pain (hyperalgesic priming) in male and female rats. J Neurosci 33:11002-11011.

Ferrari LF, Bogen O, Chu C, Levine JD (2013b) Peripheral administration of translation inhibitors reverses increased hyperalgesia in a model of chronic pain in the rat. J Pain 14:731-738.

Ferrari LF, Bogen O, Levine JD (2014) Second messengers mediating the expression of neuroplasticity in a model of chronic pain in the rat. J Pain 15:312-320.

Ferrari LF, Araldi D, Levine JD (2015a) Distinct terminal and cell body mechanisms in the nociceptor mediate hyperalgesic priming. J Neurosci 35:6107-6116.

Ferrari LF, Bogen O, Reichling DB, Levine JD (2015b) Accounting for the delay in the transition from acute to chronic pain: axonal and nuclear mechanisms. J Neurosci 35:495-507.

Ferrari LF, Khomula EV, Araldi D, Levine JD (2016) Marked sexual dimorphism in the role of the ryanodine receptor in a model of pain chronification in the rat. Sci Rep 6:31221.

Ferrari LF, Khomula EV, Araldi D, Levine JD (2018) CD44 signaling mediates high molecular weight hyaluronan-induced antihyperalgesia. J Neurosci 38:308-321.

Ferrari LF, Araldi D, Bogen O, Green PG, Levine JD (2019) Systemic morphine produces dose-dependent nociceptor-mediated biphasic changes in nociceptive threshold and neuroplasticity. Neuroscience 398:64-75.

Fishbain DA, Cole B, Lewis JE, Gao J, Rosomoff RS (2009) Do opioids induce hyperalgesia in humans? An evidence-based structured review. Pain Med 10:829-839.

Fletcher D, Martinez V (2014) Opioid-induced hyperalgesia in patients after surgery: a systematic review and a meta-analysis. Br J Anaesth 112: 991-1004.

Gaskin DJ, Richard P (2012) The economic costs of pain in the united states. J Pain 13:715-724.

Gold MS, Dastmalchi S, Levine JD (1996) Co-expression of nociceptor 
properties in dorsal root ganglion neurons from the adult rat in vitro. Neuroscience 71:265-275.

Green PG, Chen X, Alvarez P, Ferrari LF, Levine JD (2011) Early-life stress produces muscle hyperalgesia and nociceptor sensitization in the adult rat. Pain 152:2549-2556.

Hagenston AM, Simonetti M (2014) Neuronal calcium signaling in chronic pain. Cell Tissue Res 357:407-426.

Harper AA, Lawson SN (1985) Conduction velocity is related to morphological cell type in rat dorsal root ganglion neurones. J Physiol 359:31-46.

Hendrich J, Alvarez P, Joseph EK, Chen X, Bogen O, Levine JD (2013) Electrophysiological correlates of hyperalgesic priming in vitro and in vivo. Pain 154:2207-2215.

Iegorova O, Fisyunov A, Krishtal O (2010) G-protein-independent modulation of P-type calcium channels by mu-opioids in Purkinje neurons of rat. Neurosci Lett 480:106-111.

Jabbi M, Kema IP, van der Pompe G, te Meerman GJ, Ormel J, den Boer JA (2007) Catechol-o-methyltransferase polymorphism and susceptibility to major depressive disorder modulates psychological stress response. Psychiatr Genet 17:183-193.

Jensen KB, Lonsdorf TB, Schalling M, Kosek E, Ingvar M (2009) Increased sensitivity to thermal pain following a single opiate dose is influenced by the COMT val(158)met polymorphism. PLoS One 4:e6016.

Ji RR, Zhang Q, Law PY, Low HH, Elde R, Hokfelt T (1995) Expression of mu-, delta-, and kappa-opioid receptor-like immunoreactivities in rat dorsal root ganglia after carrageenan-induced inflammation. J Neurosci 15:8156-8166.

Johannes CB, Le TK, Zhou X, Johnston JA, Dworkin RH (2010) The prevalence of chronic pain in united states adults: results of an internet-based survey. J Pain 11:1230-1239.

Joseph EK, Levine JD (2010a) Mu and delta opioid receptors on nociceptors attenuate mechanical hyperalgesia in rat. Neuroscience 171:344-350.

Joseph EK, Levine JD (2010b) Hyperalgesic priming is restricted to isolectin B4-positive nociceptors. Neuroscience 169:431-435.

Khasar SG, Lin YH, Martin A, Dadgar J, McMahon T, Wang D, Hundle B, Aley KO, Isenberg W, McCarter G, Green PG, Hodge CW, Levine JD, Messing RO (1999) A novel nociceptor signaling pathway revealed in protein kinase C epsilon mutant mice. Neuron 24:253-260.

Khasar SG, Dina OA, Green PG, Levine JD (2009) Sound stress-induced long-term enhancement of mechanical hyperalgesia in rats is maintained by sympathoadrenal catecholamines. J Pain 10:1073-1077.

Khomula EV, Viatchenko-Karpinski VY, Borisyuk AL, Duzhyy DE, Belan PV, Voitenko NV (2013) Specific functioning of Cav3.2 T-type calcium and TRPV1 channels under different types of STZ-diabetic neuropathy. Biochim Biophys Acta 1832:636-649.

Khomula EV, Ferrari LF, Araldi D, Levine JD (2017) Sexual dimorphism in a reciprocal interaction of ryanodine and IP3 receptors in the induction of hyperalgesic priming. J Neurosci 37:2032-2044.

Kim D, Lim HS, Kim MJ, Jeong W, Ko S (2018) High-dose intraoperative remifentanil infusion increases early postoperative analgesic consumption: a prospective, randomized, double-blind controlled study. J Anesth 32:886-892.

Kolesnikov Y, El-Maarouf A, Rutishauser U, Pasternak G (2007) Reorganization of dorsal root ganglion neurons following chronic sciatic nerve constriction injury: correlation with morphine and lidocaine analgesia. Eur J Pharmacol 568:124-133.

Kostyuk P, Verkhratsky A (1994) Calcium stores in neurons and glia. Neuroscience 63:381-404.

Laboureyras E, Aubrun F, Monsaingeon M, Corcuff JB, Laulin JP, Simonnet G (2014) Exogenous and endogenous opioid-induced pain hypersensitivity in different rat strains. Pain Res Manag 19:191-197.

Landowne D (1993) Measuring nerve excitation with polarized light. Jpn J Physiol 43:S7-S11.

Laulin JP, Larcher A, Celerier E, Le Moal M, Simonnet G (1998) Longlasting increased pain sensitivity in rat following exposure to heroin for the first time. Eur J Neurosci 10:782-785.

Liu ZB, Liu C, Zeng B, Huang LP, Yao LH (2017) Modulation effects of cordycepin on voltage-gated sodium channels in rat hippocampal CA1 pyramidal neurons in the presence/absence of oxygen. Neural Plast 2017: 2459053.

Luarte A, Cornejo VH, Bertin F, Gallardo J, Couve A (2018) The axonal endoplasmic reticulum: one organelle-many functions in development, maintenance, and plasticity. Dev Neurobiol 78:181-208.
Mauermann E, Filitz J, Dolder P, Rentsch KM, Bandschapp O, Ruppen W (2016) Does fentanyl lead to opioid-induced hyperalgesia in healthy volunteers?: a double-blind, randomized, crossover trial. Anesthesiology 124:453-463.

Mestre C, Pelissier T, Fialip J, Wilcox G, Eschalier A (1994) A method to perform direct transcutaneous intrathecal injection in rats. J Pharmacol Toxicol Methods 32:197-200.

Munafo MR, Stevenson J (2001) Anxiety and surgical recovery. reinterpreting the literature. J Psychosom Res 51:589-596.

Nahin RL (2015) Estimates of pain prevalence and severity in adults: united states, 2012. J Pain 16:769-780.

Okudaira N, Ishizaka Y, Nishio H, Sakagami H (2016) Morphine and fentanyl citrate induce retrotransposition of long interspersed element-1. In Vivo 30:113-118.

Pan B, Guo Y, Wu HE, Park J, Trinh VN, Luo ZD, Hogan QH (2016) Thrombospondin- 4 divergently regulates voltage-gated $\mathrm{Ca} 2+$ channel subtypes in sensory neurons after nerve injury. Pain 157:2068-2080.

Parada CA, Yeh JJ, Joseph EK, Levine JD (2003a) Tumor necrosis factor receptor type-1 in sensory neurons contributes to induction of chronic enhancement of inflammatory hyperalgesia in rat. Eur J Neurosci 17:1847-1852.

Parada CA, Yeh JJ, Reichling DB, Levine JD (2003b) Transient attenuation of protein kinase cepsilon can terminate a chronic hyperalgesic state in the rat. Neuroscience 120:219-226.

Parada CA, Reichling DB, Levine JD (2005) Chronic hyperalgesic priming in the rat involves a novel interaction between cAMP and PKCepsilon second messenger pathways. Pain 113:185-190.

Petruska JC, Napaporn J, Johnson RD, Gu JG, Cooper BY (2000) Subclassified acutely dissociated cells of rat DRG: histochemistry and patterns of capsaicin-, proton-, and ATP-activated currents. J Neurophysiol 84: 2365-2379.

Petruska JC, Napaporn J, Johnson RD, Cooper BY (2002) Chemical responsiveness and histochemical phenotype of electrophysiologically classified cells of the adult rat dorsal root ganglion. Neuroscience 115:15-30.

Reichling DB, Levine JD (2009) Critical role of nociceptor plasticity in chronic pain. Trends Neurosci 32:611-618.

Roeckel LA, Le Coz GM, Gaveriaux-Ruff C, Simonin F (2016) Opioidinduced hyperalgesia: cellular and molecular mechanisms. Neuroscience 338:160-182.

Ruscheweyh R, Wilder-Smith O, Drdla R, Liu XG, Sandkuhler J (2011) Long-term potentiation in spinal nociceptive pathways as a novel target for pain therapy. Mol Pain 7:20.

Saloman JL, Scheff NN, Snyder LM, Ross SE, Davis BM, Gold MS (2016) Gi-DREADD expression in peripheral nerves produces ligand-dependent analgesia, as well as ligand-independent functional changes in sensory neurons. J Neurosci 36:10769-10781.

Scherrer G, Imamachi N, Cao YQ, Contet C, Mennicken F, O’Donnell D, Kieffer BL, Basbaum AI (2009) Dissociation of the opioid receptor mechanisms that control mechanical and heat pain. Cell 137:1148-1159.

Schmidt Y, Gaveriaux-Ruff C, Machelska H (2013) mu-opioid receptor antibody reveals tissue-dependent specific staining and increased neuronal mu-receptor immunoreactivity at the injured nerve trunk in mice. PLoS One 8:e79099.

Shutov L, Kruglikov I, Gryshchenko O, Khomula E, Viatchenko-Karpinski V, Belan P, Voitenko N (2006) The effect of nimodipine on calcium homeostasis and pain sensitivity in diabetic rats. Cell Mol Neurobiol 26: 1541-1557.

Silverman SM (2009) Opioid induced hyperalgesia: clinical implications for the pain practitioner. Pain Physician 12:679-684.

Stevens CW, Aravind S, Das S, Davis RL (2013) Pharmacological characterization of LPS and opioid interactions at the toll-like receptor $4 . \mathrm{Br} J$ Pharmacol 168:1421-1429.

Sun Q, Zhang BY, Zhang PA, Hu J, Zhang HH, Xu GY (2019) Downregulation of Glucose-6-phosphate dehydrogenase contributes to diabetic neuropathic pain through up-regulation of toll-like receptor 4 in rats. Mol Pain 15:1-12.

Suzan E, Eisenberg E, Treister R, Haddad M, Pud D (2013) A negative correlation between hyperalgesia and analgesia in patients with chronic radicular pain: is hydromorphone therapy a double-edged sword? Pain Physician 16:65-76.

Taiwo YO, Levine JD (1989) Prostaglandin effects after elimination of indi- 
rect hyperalgesic mechanisms in the skin of the rat. Brain Res 492:397399.

Taiwo YO, Bjerknes LK, Goetzl EJ, Levine JD (1989) Mediation of primary afferent peripheral hyperalgesia by the cAMP second messenger system. Neuroscience 32:577-580.

van Hecke O, Torrance N, Smith BH (2013) Chronic pain epidemiology and its clinical relevance. Br J Anaesth 111:13-18.

Velazquez-Marrero C, Ortiz-Miranda S, Marrero HG, Custer EE, Treistman SN, Lemos JR (2014) mu-opioid inhibition of Ca2 + currents and secretion in isolated terminals of the neurohypophysis occurs via ryanodinesensitive Ca2 + stores. J Neurosci 34:3733-3742.

Viatchenko-Karpinski V, Gu JG (2016) Mechanical sensitivity and electrophysiological properties of acutely dissociated dorsal root ganglion neurons of rats. Neurosci Lett 634:70-75.

Watkins LR, Hutchinson MR, Rice KC, Maier SF (2009) The "toll" of opioid-induced glial activation: improving the clinical efficacy of opioids by targeting glia. Trends Pharmacol Sci 30:581-591.

Weber L, Yeomans DC, Tzabazis A (2017) Opioid-induced hyperalgesia in clinical anesthesia practice: what has remained from theoretical concepts and experimental studies? Curr Opin Anaesthesiol 30:458-465.
Woolf CJ, Ma Q (2007) Nociceptors-noxious stimulus detectors. Neuron 55:353-364.

Yi P, Pryzbylkowski P (2015) Opioid induced hyperalgesia. Pain Med $16:$ S32-S36.

Yildirim V, Doganci S, Cinar S, Eskin MB, Ozkan G, Eksert S, Ince ME, Dogrul A (2014) Acute high dose-fentanyl exposure produces hyperalgesia and tactile allodynia after coronary artery bypass surgery. Eur Rev Med Pharmacol Sci 18:3425-3434.

Yu H, Pan B, Weyer A, Wu HE, Meng J, Fischer G, Vilceanu D, Light AR, Stucky C, Rice FL, Hudmon A, Hogan Q (2015) CaMKII controls whether touch is painful. J Neurosci 35:14086-14102.

Zaremba M, Ruiz-Velasco V (2019) Opioid-mediated modulation of acidsensing ion channel currents in adult rat sensory neurons. Mol Pharmacol 95:519-527.

Zhang MD, Tortoriello G, Hsueh B, Tomer R, Ye L, Mitsios N, Borgius L, Grant G, Kiehn O, Watanabe M, Uhlen M, Mulder J, Deisseroth K, Harkany T, Hokfelt TG (2014) Neuronal calcium-binding proteins 1/2 localize to dorsal root ganglia and excitatory spinal neurons and are regulated by nerve injury. Proc Natl Acad Sci U S A 111:E1149-E1158.

Zylicz Z, Twycross R (2008) opioid-induced hyperalgesia may be more frequent than previously thought. J Clin Oncol 26:1564. 